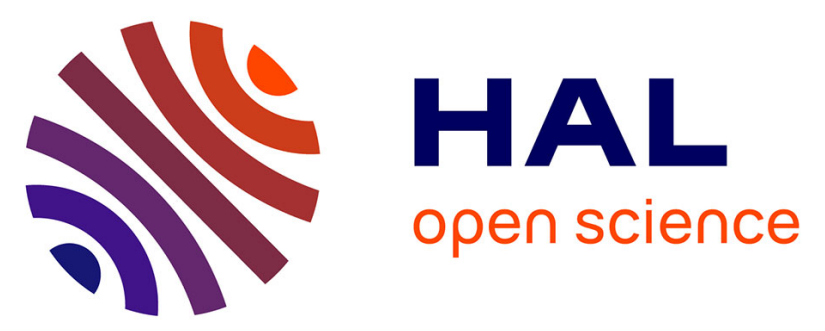

\title{
Efficient gene expression from integration-deficient lentiviral vectors in the spinal cord.
}

\author{
H. Peluffo, E. Foster, S. G. Ahmed, N. Lago, T. H. Hutson, L. Moon, P. Yip,
} K. Wanisch, V. Caraballo-Miralles, G. Olmos, et al.

\section{- To cite this version:}

H. Peluffo, E. Foster, S. G. Ahmed, N. Lago, T. H. Hutson, et al.. Efficient gene expression from integration-deficient lentiviral vectors in the spinal cord.. Gene Therapy, 2013, 20 (6), pp.645-57. 10.1038/gt.2012.78 . pasteur-00844784

\section{HAL Id: pasteur-00844784 https://hal-riip.archives-ouvertes.fr/pasteur-00844784}

Submitted on 14 Jan 2014

HAL is a multi-disciplinary open access archive for the deposit and dissemination of scientific research documents, whether they are published or not. The documents may come from teaching and research institutions in France or abroad, or from public or private research centers.
L'archive ouverte pluridisciplinaire HAL, est destinée au dépôt et à la diffusion de documents scientifiques de niveau recherche, publiés ou non, émanant des établissements d'enseignement et de recherche français ou étrangers, des laboratoires publics ou privés. 


\title{
ORIGINAL ARTICLE
}

\section{Efficient gene expression from integration-deficient lentiviral vectors in the spinal cord}

\author{
H Peluffo ${ }^{1,2,3,6}$, E Foster ${ }^{4,6}$, SG Ahmed ${ }^{1}$, N Lago ${ }^{4}$, TH Hutson ${ }^{4}$, L Moon ${ }^{4}$, P Yip ${ }^{4}$, K Wanisch ${ }^{1}$, V Caraballo-Miralles ${ }^{1,5}$, G Olmos $^{5}$, J Lladó $^{5}$, \\ SB McMahon ${ }^{4}$ and RJ Yáñez-Muñoz ${ }^{1}$
}

Gene transfer to spinal cord cells may be crucial for therapy in spinal muscular atrophy, amyotrophic lateral sclerosis and spinal cord injury. Lentiviral vectors are efficient for transduction of a variety of cells, but like all integrating vectors they pose a risk of insertional mutagenesis. Integration-deficient lentiviral vectors (IDLVs) remain episomal but retain the transduction efficiency of standard integrating lentiviral vectors, particularly when the episomes are not diluted out through repeated cell division. We have now applied IDLVs for transduction of spinal cord in vitro, in explants and in vivo. Our results demonstrate similar efficiency of eGFP expression from integrating lentiviral vectors and IDLVs in most cell types analyzed, including motor neurons, interneurons, dorsal root ganglia (DRG) neurons and astroglia. IDLV-mediated expression of pro-glial-cell-derived neurotrophic factor (Gdnf) rescues motor neuron cultures from death caused by removal of exogenous trophic support. IDLVs also mediate efficient RNA interference in DRG neuron cultures. After intraparenchymal injection in the rat and mouse cervical and lumbar regions in vivo, transduction is mainly neuronal, with both motor neurons and interneurons being efficiently targeted. These results suggest that IDLVs could be efficient and safer tools for spinal cord transduction in future therapeutic strategies.

Gene Therapy (2013) 20, 645-657; doi:10.1038/gt.2012.78; published online 18 October 2012

Keywords: integration-deficient lentiviral vector; spinal cord; motor neuron; eGFP; GDNF; RNA interference

\section{INTRODUCTION}

HIV-1-derived and other lentiviral vectors are able to mediate long-term in vivo expression in various tissues, including nondividing ones. ${ }^{1,2}$ When pseudotyped with the vesicular stomatitis virus $\mathrm{G}$ protein (VSV-G), lentiviral vectors transduce a broad range of cells, which in the central nervous system (CNS) includes neurons and some glial cells. ${ }^{1-4}$ Lentiviral vectors have been used in several therapeutic paradigms, showing very promising results. $^{5-7}$ In particular, they have displayed neuroprotective potential for diverse spinal cord neuropathologies, rescuing for instance motor neurons in amyotrophic lateral sclerosis models by expressing shRNA. ${ }^{8,9}$ Moreover, in a model of spinal cord injury, the overexpression of the transcription factor retinoid receptor $\beta 2$ in cortical neurons induced enhanced regeneration and functional recovery. ${ }^{10}$ Neuroprotection with lentiviral vectors can be achieved not only by direct injection into the spinal cord, ${ }^{9}$ but also by intramuscular injection of rabies $G$ envelope protein pseudotyped lentiviral vectors, which reach the spinal motor neurons by retrograde transport. ${ }^{8}$ Lentiviral vectors have been used in a clinical trial attempting at inducing anti-HIV protection, with promising results, ${ }^{11}$ and have shown therapeutic efficacy in a small-scale trial for X-linked adrenoleukodystrophy. ${ }^{12}$

Although the integration capacity of lentiviral vectors enables stable transduction of target cells, it also carries a finite risk of causing insertional mutagenesis. ${ }^{13}$ Integration-deficient lentiviruses can be produced by using mutant versions of integrase. ${ }^{14}$ Class I integrase mutations affect DNA cleavage and joining, but do not affect the amount of viral DNA produced. ${ }^{15}$ Integration-deficient lentiviral vectors (IDLVs) can be similarly produced. The vectors thus produced fail to integrate in the target cell genome but are instead efficiently converted into circular episomes (see ref. ${ }^{16}$ for a review). Such IDLVs have shown to be capable of efficient gene expression in cell culture, particularly in growth-arrested cells. ${ }^{17-19}$ More important, IDLVs mediate longlasting transduction of CNS and muscle cells in vivo. ${ }^{20-22}$

We are particularly interested in transduction of spinal cord for application to pain, neurodegeneration and spinal cord injury, paradigms in which IDLVs could be potent and safe tools for gene delivery. To study whether there are differences in transduction efficiency or toxicity between integration-proficient lentiviral vectors and IDLVs, we have conducted an extensive in vitro and in vivo analysis in rat and mouse using vectors expressing eGFP, growth factors and shRNAs. Our results show similar efficiency and toxicity profiles for transduction of motor, inter- and dorsal root ganglia (DRG) neurons, astrocytes and oligodendrocytes, and some differences in microglia. These results indicate that IDLVs are highly suited for applications involving spinal cord transduction.

\section{RESULTS}

Transduction of purified motor neurons in culture

Purified motor neuron cultures were exposed to increasing doses of VSV-G-pseudotyped integration-deficient (IN - ) and integrating $(\mathrm{IN}+)$ lentiviral vectors encoding eGFP, and 3 days later

\footnotetext{
${ }^{1}$ School of Biological Sciences, Royal Holloway-University of London, London, UK; ${ }^{2}$ Department of Histology and Embryology, Faculty of Medicine, UDELAR, Montevideo, Uruguay; ${ }^{3}$ Neurodegeneration Laboratory, Institut Pasteur de Montevideo, Montevideo, Uruguay; ${ }^{4}$ Neurorestoration Group, Wolfson Centre for Age-Related Diseases, King's College London, London, UK and ${ }^{5}$ Department of Biology/IUNICS, Universitat de les Illes Balears, Palma, Spain. Correspondence: Dr RJ Yáñez-Muñoz, School of Biological Sciences, Royal Holloway-University of London, Egham, Surrey TW20 OEX, UK.

E-mail: rafael.yanez@rhul.ac.uk

${ }^{6}$ These authors contributed equally to this work.

Received 7 June 2012; revised 14 August 2012; accepted 5 September 2012; published online 18 October 2012
} 
transduction efficiency and viability were evaluated. Similar dosedependent increases in the percentage of eGFP-expressing cells were observed with both $\mathrm{IN}-$ and $\mathrm{IN}+$ vectors (Figures 1a and $b$ ), reaching a maximum value of $\sim 50-60 \%$ at multiplicity of infection (MOI) 25. Likewise, purified motor neuron cultures were exposed to rabies $\mathrm{G}$ protein-pseudotyped IN - and IN + lentiviral vectors encoding eGFP. Again $\sim 50 \%$ of the motor neurons were transduced regardless of integration proficiency (data not shown). a
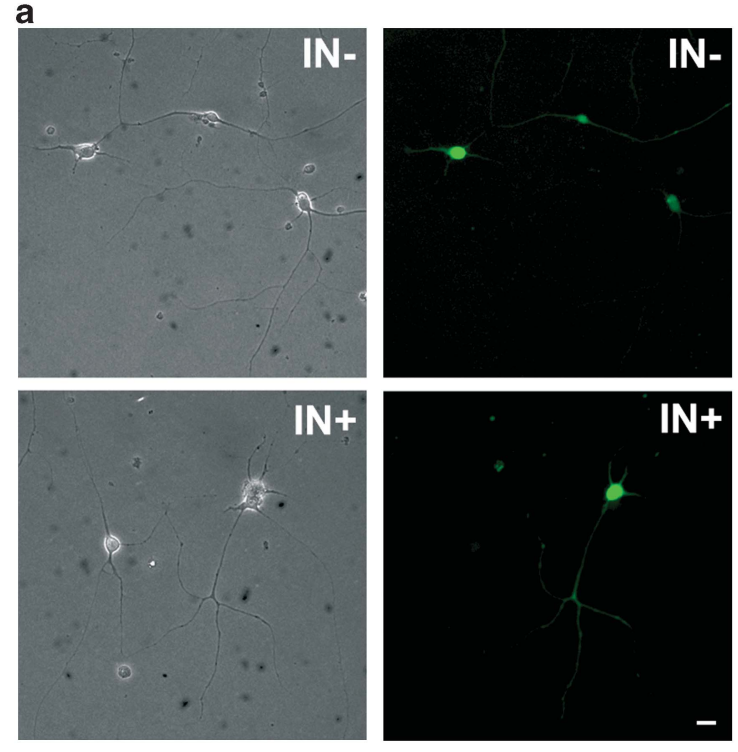

b

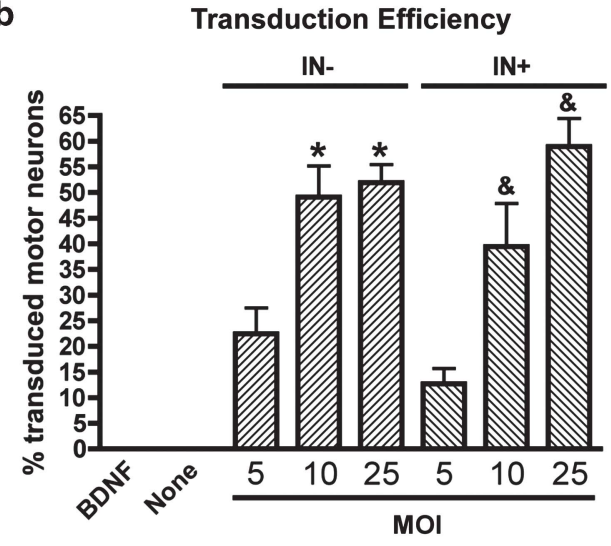

Cell Viability

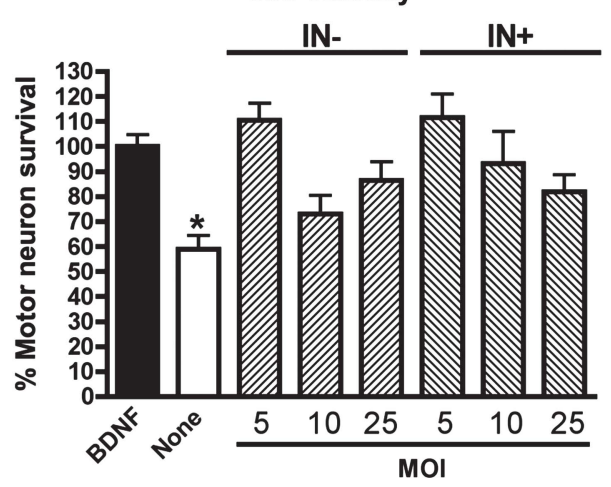

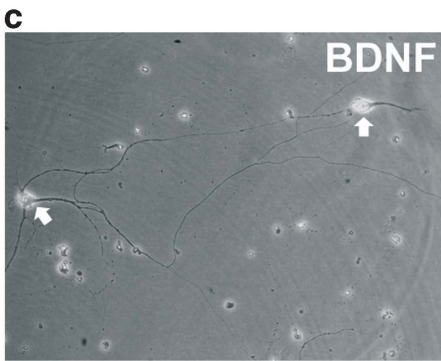
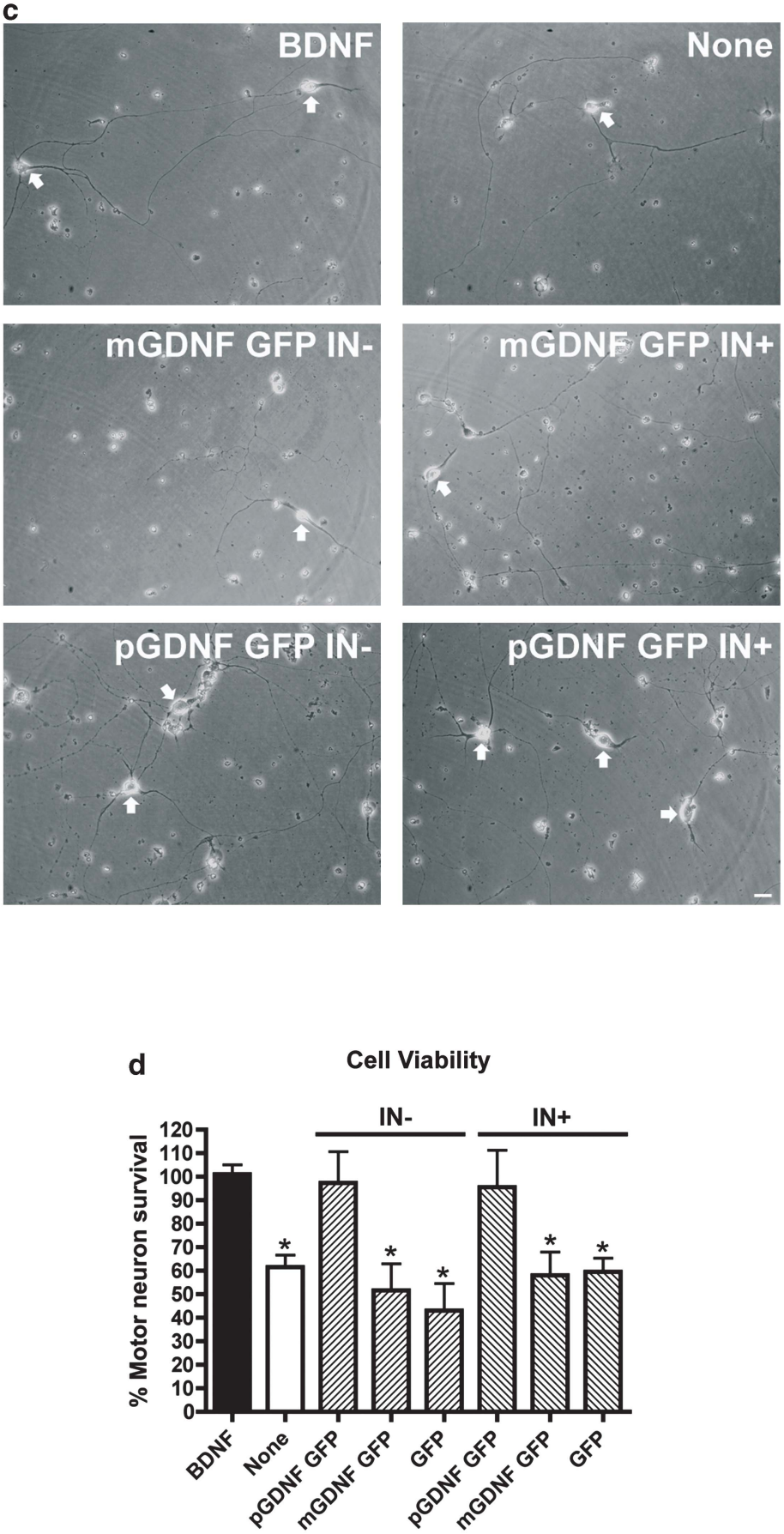

Figure 1. Transduction in motor neuron cultures. (a, b) Purified motor neuron cultures were exposed to increasing doses of IN - and IN + vectors, and the transduction efficiency and cell viability were evaluated by fluorescence and direct cell counts. Motor neuron transduction was dose-dependent but no significant differences were observed between IN - and IN + vectors ( $b$, * $P<0.05$ when compared with IN MOI 5; ${ }^{\&} P<0.05$ when compared with $\left.\mathrm{IN}+\mathrm{MOI} 5\right)$. A tendency towards reduced survival that did not reach statistical significance was observed for the higher doses of both vectors. (c, d) Motor neuron cultures were exposed to IN - and IN + vectors expressing eGFP, eGFP plus the non-secretable mature form of GDNF (mGdnf), or eGFP plus the full-length precursor of GDNF (pGdnf). Three days later, exogenous trophic factor support was removed, and only pGdnf-GFP IN - and IN + vectors prevented, to a similar extent, the ensuing neuronal death ( $d,{ }^{*} P<0.05$ when compared with control with exogenous brain-derived neurotrophic factor, BDNF). Arrows in (c) indicate motor neurons with significant neurite outgrowth. Scale bars: $20 \mu \mathrm{m}$. 
In an attempt to increase transduction efficiency of motor neurons we used polybrene, a reagent known to improve vector transduction in at least some cell types. However, incubation of motor neurons with polybrene $\left(2-8 \mu \mathrm{g} \mathrm{ml}^{-1}\right)$ was extremely toxic and no live cells could be recovered.

Viability of transduced motor neurons was estimated by direct counting of cells under phase contrast. A trend for reduced viability was observed with both $\mathrm{IN}$ - and $\mathrm{IN}+$ vector types as the $\mathrm{MOI}$ increased above 10 , but no statistical significance could be demonstrated when compared with control conditions (Figure 1b). The overall morphology and neuritic development of transduced motor neurons did not show gross alterations with any of the vectors. Similar results were also obtained with rabies pseudotyped vectors (data not shown).

The overexpression of reporter transgenes like eGFP is a useful tool, but to assess functional efficiency in transduced cells we chose to overproduce a key protein for cultured motor neurons, a growth factor. Motor neurons undergo cell death after exogenous trophic factor deprivation, which can be rescued by autocrine expression of growth factor. We transduced motor neuron cultures with lentiviral vectors overexpressing pro-glial-cellderived neurotrophic factor (Gdnf) variants, and $72 \mathrm{~h}$ later the exogenous trophic factor support was withdrawn. Regardless of vector integration proficiency, cell death was completely prevented when full-length Gdnf precursor was overexpressed (Figures 1c and d). Moreover, qualitative evaluation suggested enhanced neurite outgrowth (see arrows in Figure 1c). Cultures exposed to the overexpression of eGFP or mature Gdnf (which cannot be secreted) did not show any significant effect on motor neuron rescue under these conditions (Figures $1 \mathrm{c}$ and $\mathrm{d}$ ).

Transduction of cultured DRG neurons

Cultures enriched in DRG neurons were exposed to increasing doses of VSV-G-pseudotyped IN - and IN + lentiviral vectors overexpressing eGFP, and evaluated for eGFP production and cell viability at several time points (Figure 2). A dose- and timedependent increase in the number of transduced DRG neurons was observed by direct cell counts, showing very similar profiles for IN - and IN + vectors (Figure 2b). After 8 days in culture, both vector types transduced $\sim 80 \%$ of DRG neurons at MOI 10, which did not differ significantly from what was observed at MOI 50 (Figure 2b). Densitometrical analysis of eGFP levels in neuronal soma also showed increased production of the transgenic protein with increased $\mathrm{MOI}$ and time in culture, though no significant difference was observed between IN - and IN + vectors (Figure 2b).

DRG cultures exposed to rabies $G$ protein pseudotyped vectors also showed a dose- and time-dependent increase in transduction efficiency (Figures $2 \mathrm{c}$ and $\mathrm{d}$ ). After 8 days in culture, both $\mathrm{IN}-$ and IN + vectors rendered $\sim 30-40 \%$ of DRG neurons expressing eGFP at $\mathrm{MOI} 10$, regardless of integration proficiency. Densitometrical analysis of eGFP in neuronal soma also showed increased production of the transgenic protein with increased $\mathrm{MOI}$ and time in culture, but no significant difference was observed between IN - and IN + vectors (Figure 2d). Regarding the possible toxic effect of virus transduction, no significant decrease of DRG neuron viability was observed after trypan blue staining (Figure 2d), and overall morphology and neuritic development showed no gross alterations (Figure $2 \mathrm{c}$ ).

To test whether IDLVs are able to support efficient expression from RNA pol III promoters, we constructed lentiviral vectors with shRNA expression cassettes driven by the human $\mathrm{H} 1$ promoter. When DRG neuronal cultures were exposed to IN - and IN + lentiviral vectors (MOI 50) overexpressing eGFP and any one of three different shRNAs against the channel Transient receptor potential cation channel subfamily V member 1 (Trpv1) mRNA, an effective decrease in the number of neurons immunoreactive for Trpv1 was observed when compared with cultures not exposed to lentiviral vectors or cultures exposed to control lentiviral vectors.
IN - and IN + vectors showed a similar $75 \%$ reduction of the percentage of eGFP-expressing neurons which co-expressed Trpv1 when any of the three shRNAs were overexpressed (Figures $2 \mathrm{e}$ and f).

Transduction of cultured glial cells

For the analysis of transduction efficiency in glial cells, we prepared cell cultures highly enriched in astroglial or microglial cells and transduced them with eGFP-expressing IN - and IN + lentiviral vectors. Both vector types showed very high transduction efficiency in astroglial cultures, reaching $47 \pm 2 \%$ and $59 \pm 9 \%$, respectively, at $\mathrm{MOI} 1$ (Figures $3 \mathrm{a}$ and $\mathrm{b}$ ). Increasing the vector dose showed that essentially $100 \%$ of the cells could be transduced with either vector using $\mathrm{MOI} 3$ or higher. The highest doses showed enhanced levels of eGFP fluorescence per cell. No evident alteration in astrocyte morphology was observed after transduction with any of the lentiviral vectors. Vector toxicity was studied by MTT staining. There was a trend correlating vector dose and toxicity, and reductions in viability reached statistical significance with high doses of IN - vector (Figure 3c).

Transduction of microglial cultures showed a dose-dependent increase of eGFP expression, reaching maximum values around $65 \%$ with IN + vectors at MOI 10 (Figures $4 \mathrm{a}$ and b). Transduction efficiency was lower with IN - vectors compared with $\mathrm{IN}+$ vectors, not only regarding the percentage of cells transduced but also the eGFP expression level observed. It is possible that this reduction in transduction efficiency was related to enhanced toxicity. Morphologically, IN - vectors caused some cell shrinkage and round morphology at MOI 5 (data not shown) and significant cell detachment and cell death at MOI 10 (observed under phase microscopy; Figure 4c). IN - vectors showed a trend to reduced MTT viability with increasing dose (Figure 4d). Polybrene $\left(8 \mu \mathrm{g} \mathrm{ml}^{-1}\right)$ was highly toxic to microglial cells, and thus no increase in transduction efficiency could be achieved by this method. When mixed glial cultures were transduced, oligodendrocytes (identified with adenomatous polyposis coli (APC) co-staining) were also found to express eGFP (data not shown).

Transduction of postnatal organotypic cultures and embryonic explants of rat spinal cord

To study transduction efficiency in a culture in which motor neurons, interneurons, astrocytes, microglia and oligodendrocytes are present in a tridimensional architecture, we prepared organotypic cultures from postnatal (P8) rat spinal cord and exposed them to the IN - or IN + lentiviral vectors. Organotypic cultures preserve interactions between neurons and glia; thus, they offer the advantages of an in vitro system resembling the in vivo environment. Motor neurons in the organotypic spinal cord sections were identified by SMI-32 immunostaining, their morphology and size $(>25 \mu \mathrm{m})$ and their localization in the ventral horn, as previously described. ${ }^{23}$ MAP-2-immunopositive cells smaller than $25 \mu \mathrm{m}$ were counted as interneurons. Astrocytes and microglia were identified on the basis of glial fibrillary acidic protein (GFAP) and IBA-1 immunoreactivity, respectively (Figure 5a). We studied the co-localization of SMI-32, MAP-2, GFAP and IBA-1 with eGFP to study the transduction efficiency of IN - and IN + lentiviral vectors (Figure 5a). Motor neurons and astrocytes were transduced with high efficiency (c. 90\%), while microglia and interneurons were less efficiently transduced (c. 65\%; Figures 5a and b). No difference in transduction efficiency was observed between IN - and IN + vectors for any of these cell types. The viability of motor neurons was studied in these organotypic cultures after exposure to $\mathrm{IN}$ - or IN + lentiviral vectors. Motor neurons were identified following the same criteria as above, and cell counts were referred to control cultures. Motor neuron viability was slightly reduced in vector-treated samples, 
but no significant differences between the groups were found (Figure 5c).

When embryonic (E15) rat spinal cord explants are placed on plates covered with polyornithine and laminin some cells migrate outside the cord, allowing the identification of isolated motor neurons in co-culture with astrocytes, microglia and oligodendrocytes. Motor neurons were identified on the basis of SMl-32 immunoreactivity and morphology, ${ }^{24}$ while astrocytes, microglia and oligodendroglia were identified on the basis of their immunoreactivity for GFAP, IBA-1 and GalC, respectively. All
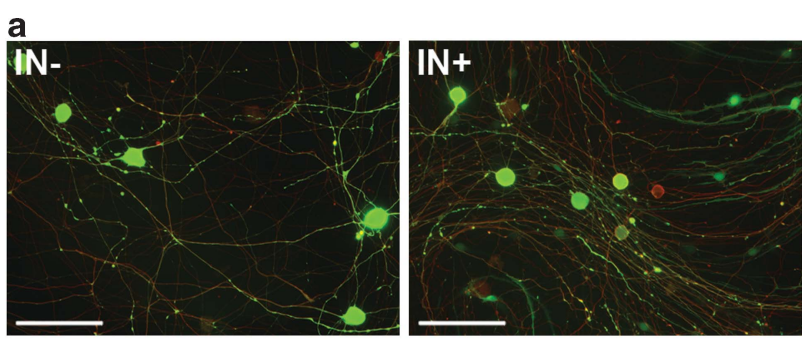

b

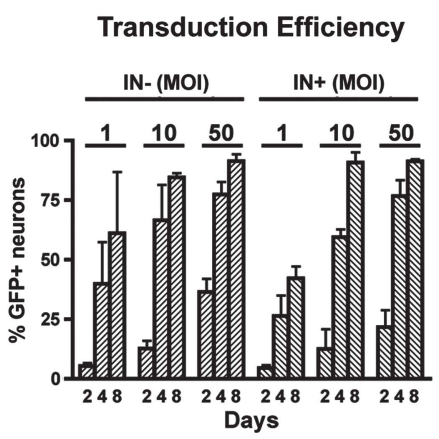

Expression Level

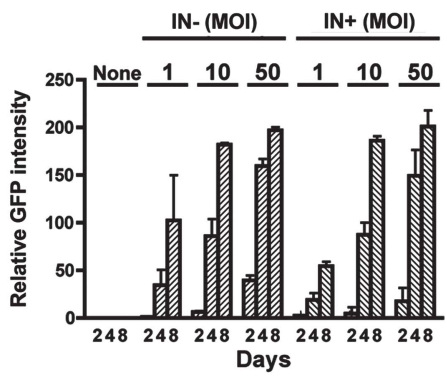

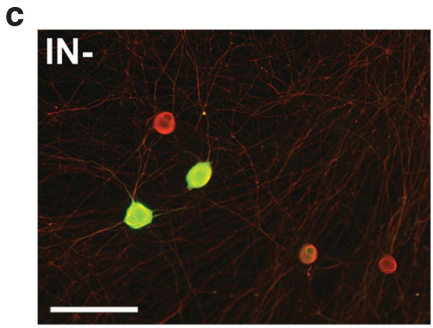

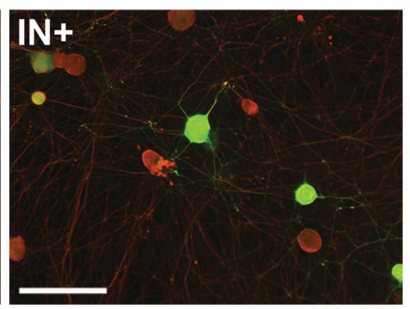

d

Transduction Efficiency

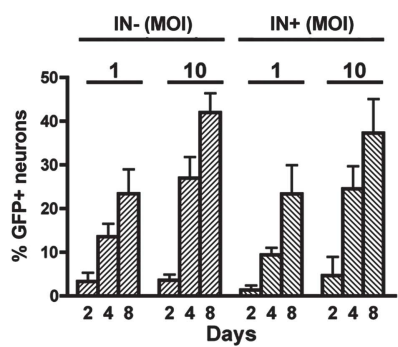

Expression Level
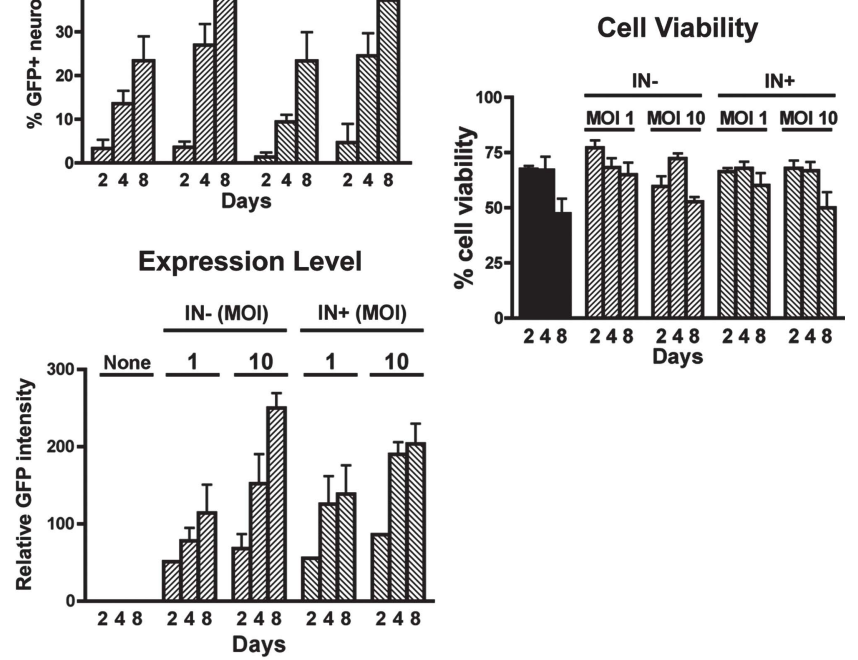

e
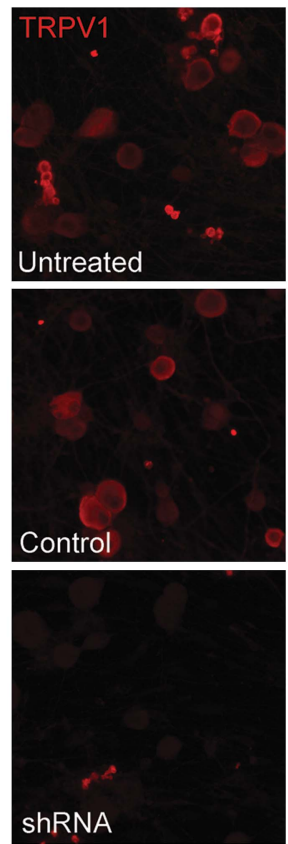
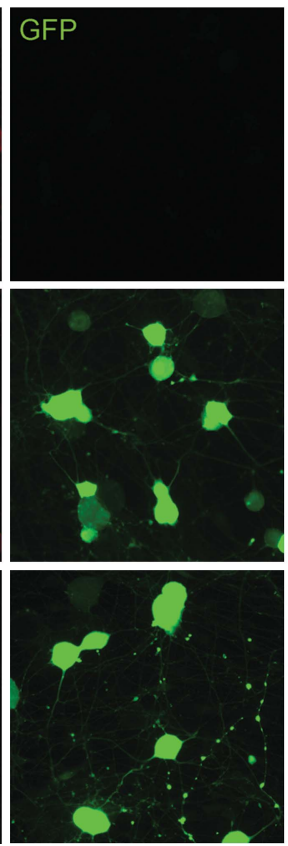
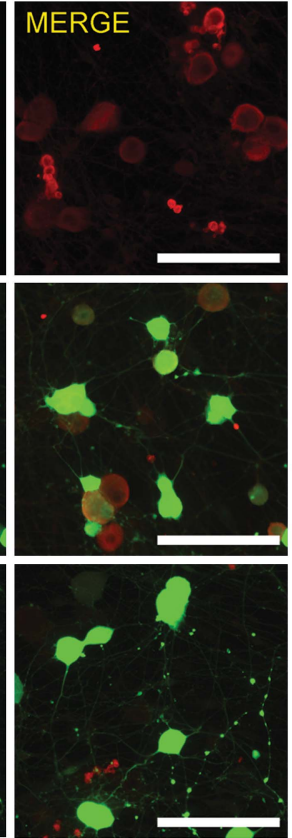

RNAi against TRPV1

\section{f}

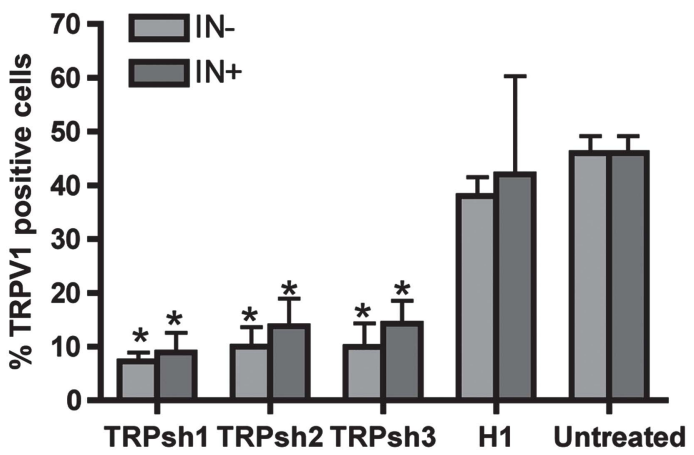


these cell types were efficiently transduced by the lentiviral vectors, regardless of their integration proficiency (Figures $5 \mathrm{~d}$ and e). Motor neurons and microglia were very efficiently transduced ( $>90 \%$ of total cells were positive for eGFP). Astrocytes and oligodendrocytes were transduced with about $60 \%$ efficiency (Figures $5 \mathrm{~d}$ and e). No evidence of toxicity was observed.

\section{In vivo transduction}

To compare their transduction efficiency in vivo, IN - and IN + VSV-G-pseudotyped lentiviral vectors were injected into the ventral horn of the cervical spinal cord of adult rats. In all, 2, 4 and 8 weeks later, eGFP production was assessed by immunofluorescence (Figure 6a). The spinal cord was efficiently transduced by both IN - and IN + vectors; however, it is important to note that in spite of finely controlled experimental procedures, variations occurred in relation to transduction efficiency and location of gene marking, even between animals of the same group (see Discussion). The overall eGFP production in white and gray matter was measured at 2 and 8 weeks post-injection by semi-quantitative densitometrical analysis of fluorescence in antieGFP-stained sections, and no significant differences were observed between vectors or time points (Figure $6 \mathrm{~b}$ ). The same was true for the quantification of the total area of eGFP immunofluorescence (Figure 6b), the percentages of transduced neurons (20-30\% according to double staining for NeuN and eGFP; Figure 6c) and motor neurons (20-40\%, double staining for ChAT and eGFP; Figures $6 c$ and d). Regarding glial cell types, very few microglial cells were transduced, as observed with double staining for eGFP and IBA-1 (Figure 6d). Astrocytes were the main glial cell type transduced, as evidenced by double staining with eGFP and GFAP (Figure 6d). Of note, APC-positive oligodendrocytes were also transduced at moderate efficiency (Figure $6 \mathrm{~d}$ ). Rabies pseudotyped IN - and IN + lentiviral vectors were also evaluated for their transduction efficiency following direct intraparenchymal injection in the rat cervical spinal cord. They mediated similar levels of transduction as the VSV-G-pseudotyped vectors and exhibited strong neuronal tropism (data not shown).

The lumbar region of the spinal cord is of particular relevance to spinal muscular atrophy because of the degeneration of $\alpha$ motor neurons observed at this location in the disease. We assessed transduction efficiency of IN - and IN + VSV-G-pseudotyped lentiviral vectors encoding eGFP in both rats and mice following direct injection in the lumbar spinal cord (Figure 7). No significant

\section{a}
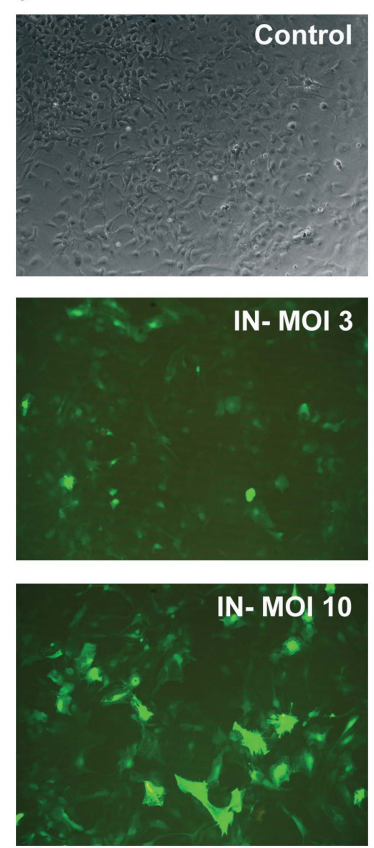
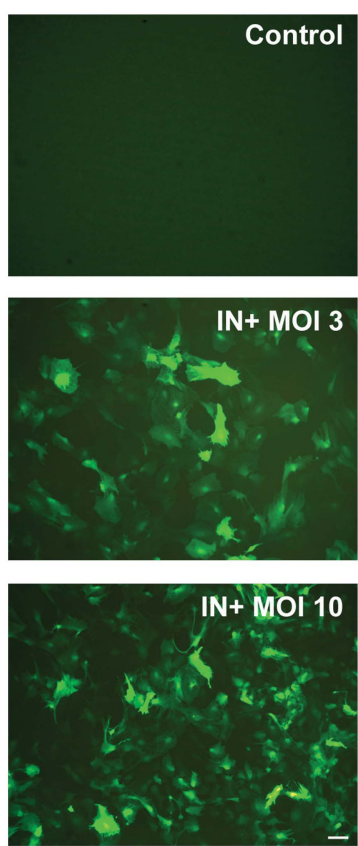

b
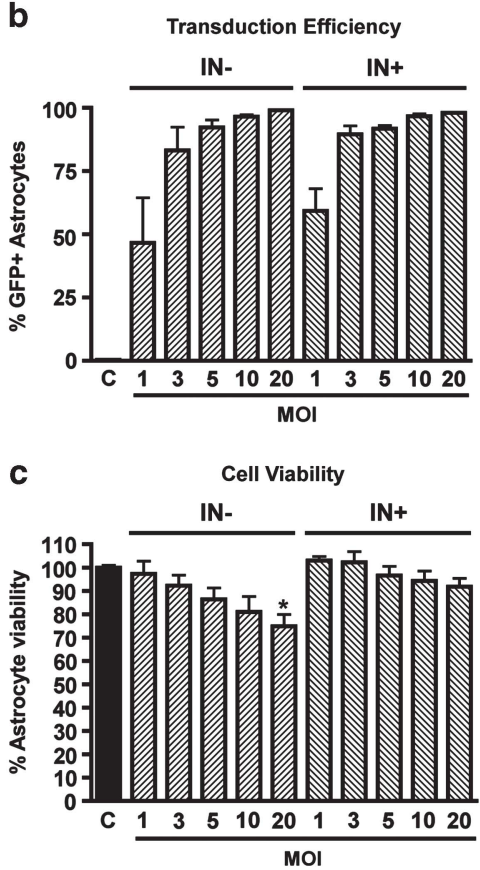

Figure 3. Transduction of cultured astrocytes. $(\mathbf{a}, \mathbf{b})$ Astroglial cultures were exposed to the indicated doses of IN - or IN + lentiviral vectors and 3 days later analyzed for eGFP production. A dose-dependent increase in transduction was observed with both IN - and IN + vectors, with no significant difference in transduction efficiency between vectors. (c) Cell viability was assessed by MTT assay. Only the highest dose of IN - vector showed a significant reduction in cell viability. Scale bar: $100 \mu \mathrm{m}$.

Figure 2. Transduction of DRG neuron cultures: (a) Representative images showing cultured DRG neurons 8 days after transduction with VSVG-pseudotyped IN - and IN + vectors (MOI 10). Neurons were labeled using antibodies against the pan-neuronal marker $\beta I I I$ tubulin (red) and transduced cells were identified by eGFP (green) fluorescence. (b) Quantification of percentage of eGFP-expressing neurons (top panel) and eGFP fluorescence intensity (bottom panel) revealed no significant differences between the two vector forms. (c) Representative images showing DRG neurons 8 days after transduction with rabies-G pseudotyped IN - and IN + vectors (MOI 10). (d) Quantification of percentage of eGFP-positive neurons (top left panel) and eGFP fluorescence intensity (bottom left panel) revealed no differences between IN - and IN + forms of rabies $\mathrm{G}$ pseudotyped vectors. No evidence of significant toxicity due to rabies-G pseudotyped vector transduction was observed in a trypan blue exclusion assay (right panel). (e) IN - vectors are able to drive robust RNAi in cultured DRG neurons. Representative images reveal a strong reduction in TRPV1 immunoreactivity (red) in cells transduced with IN - vectors expressing an shRNA targeting the TRPV1 mRNA (bottom) compared with cells transduced with control vectors (middle) and untreated cells (top). (f) Quantification of the number of TRPV1immunoreactive DRG neurons shows $>75 \%$ knockdown by three different TRPV1 shRNA sequences compared with control vectors and untreated cells $\left({ }^{*} P<0.05\right.$ when compared with control vector $\mathrm{H} 1$ or non-treated cells). Scale bars: $100 \mu \mathrm{m}$. 

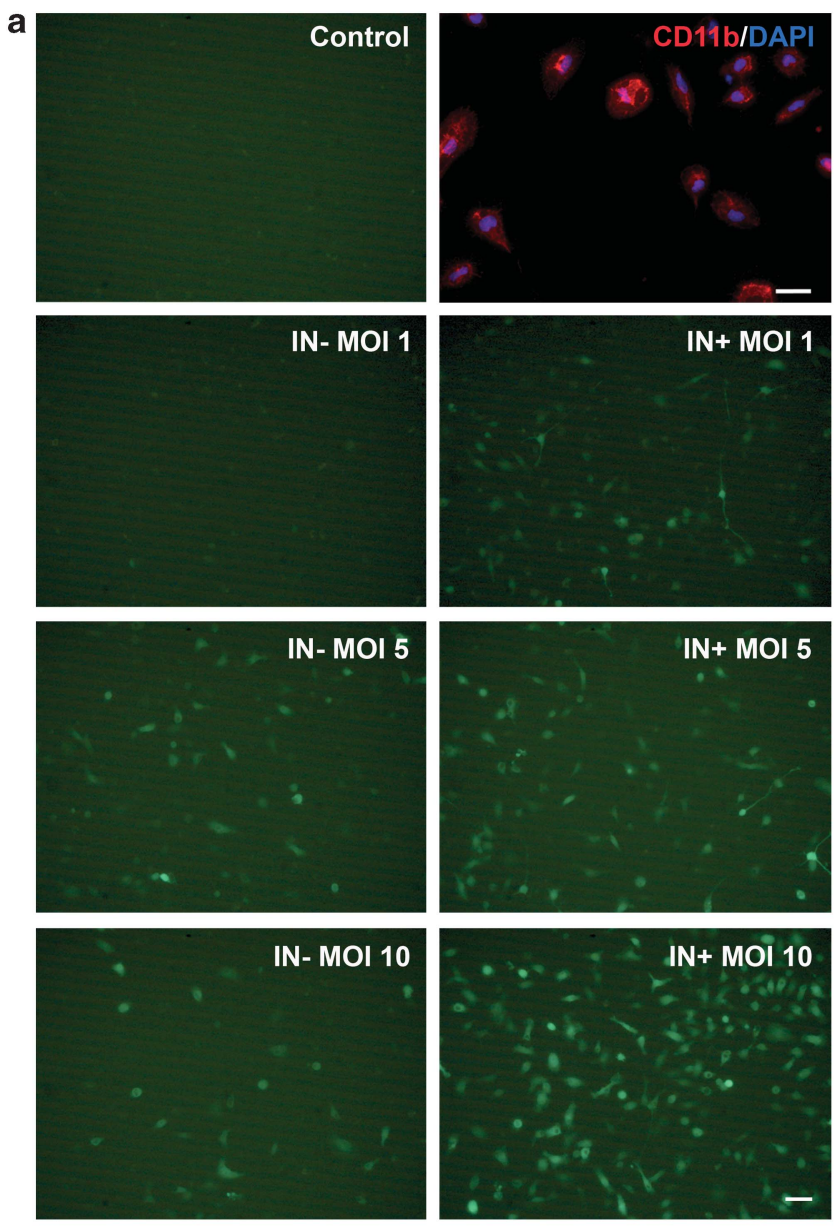

b

Transduction Efficiency

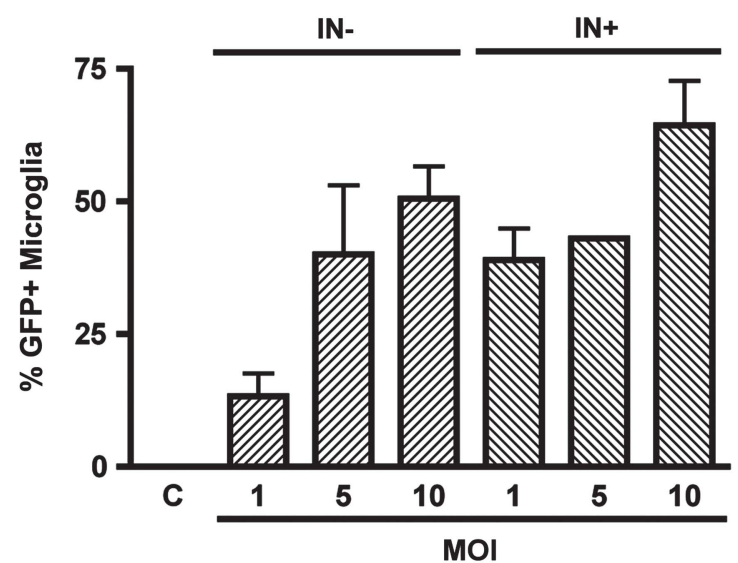

C
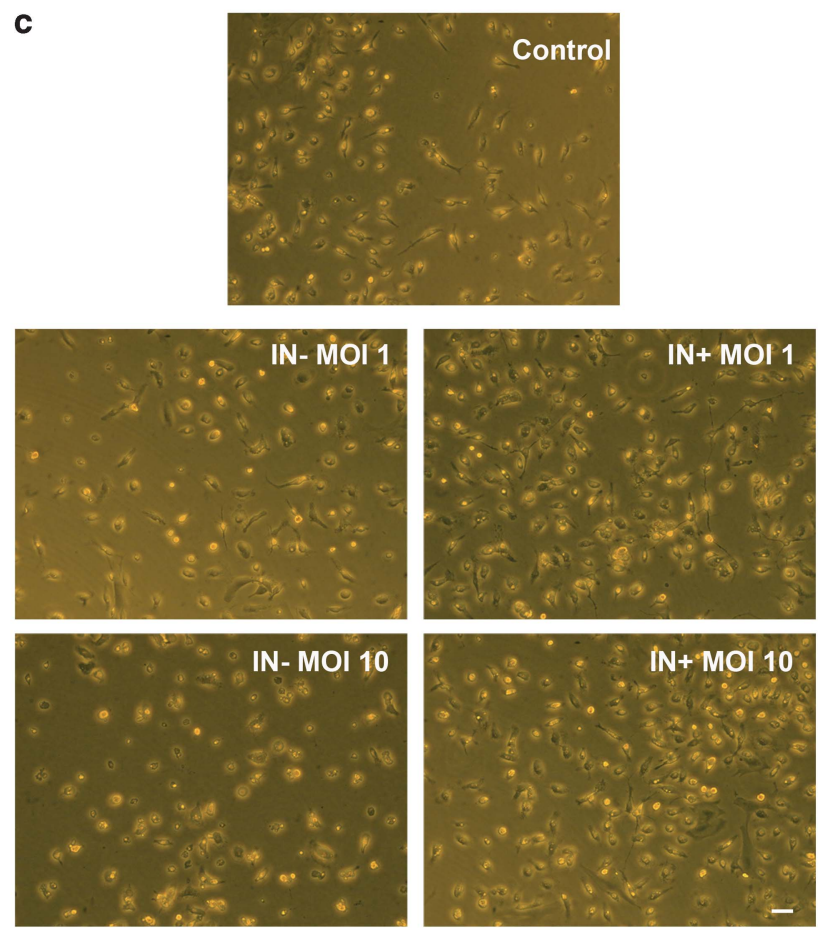

Cell Viability

d

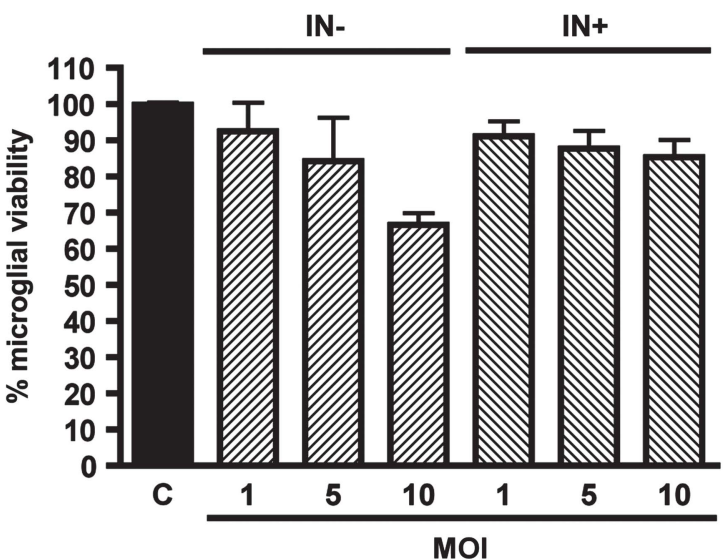

Figure 4. Transduction of microglia in vitro. $(\mathbf{a}, \mathbf{b})$ Microglial cultures were exposed to the indicated doses of IN - or IN + lentiviral vectors and 3 days later analyzed for eGFP production. A dose-dependent increase in transduction was observed with both IN - and IN + vectors, with no significant difference between the vectors. (c) Cell viability assessment by phase-contrast microscopy. (d) Viability assessment by MTT assay. IN - vectors caused some cell shrinkage and a non-significant trend towards reduction in MTT viability with increasing vector dose. Scale bars: $30 \mu \mathrm{m}$.

differences were observed regardless of vector integration proficiency. Similarly to what we observed in the cervical region, neurons (c. $20 \%$ in rat, c. $30 \%$ in mouse) and motor neurons (c. $40 \%$ in rat, c. $55 \%$ in mouse) were efficiently transduced (Figures $7 \mathrm{~b}$ and $\mathrm{c}$ ). Lower levels of transduction were noted in astrocytes and oligodendrocytes (Figure 7d).

\section{DISCUSSION}

The use of IDLVs is a promising paradigm to overcome insertional mutagenesis, particularly when tissues with low replication rates such as the nervous system are targeted. Here, we show that the in vitro and in vivo transduction efficiency of IDLVs and integration-proficient lentiviral vectors is similar for several 

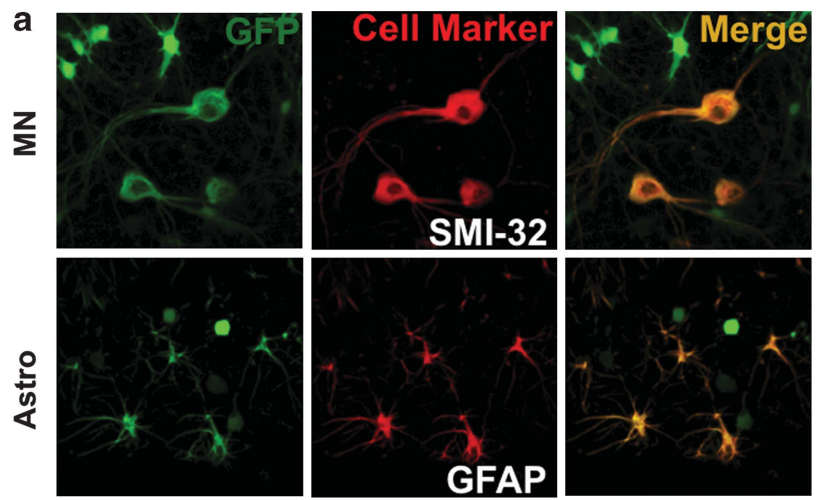

d
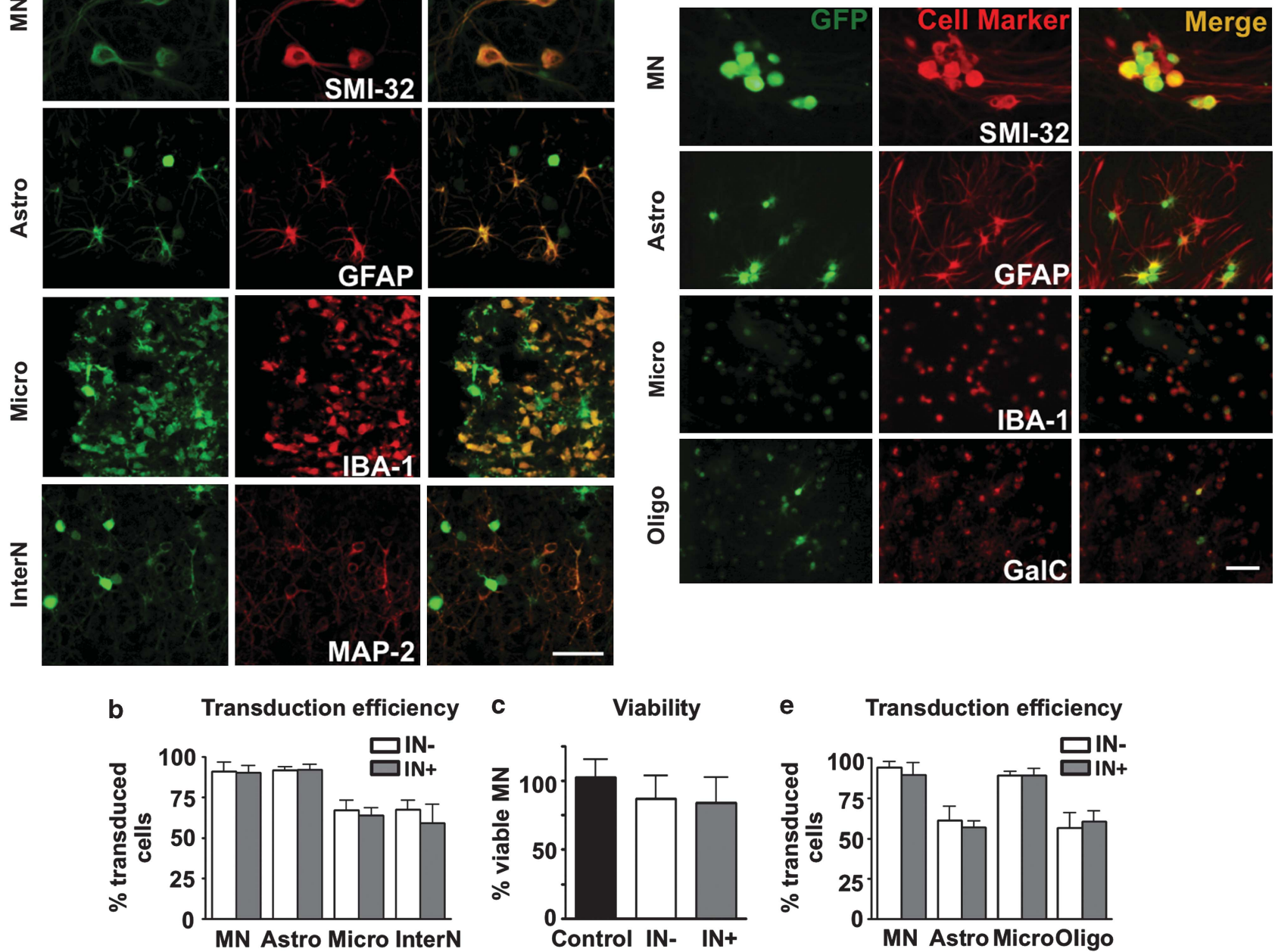

Figure 5. Transduction in postnatal organotypic cultures and embryonic explants. (a) Transduction by lentiviral vectors in postnatal organotypic cultures. Immunofluorescence for SMI-32, GFAP, IBA-1 and MAP-2 (red) and eGFP fluorescence (green) allowed the identification of transduced motor neurons (MN), astroglia (Astro), microglia (Micro) and interneurons (InterN), respectively. (b) Transduction efficiency in postnatal organotypic cultures. Percentages of SMI-32, GFAP, IBA-1 or MAP-2-positive cells co-localizing with eGFP. Bars represent the mean \pm s.e.m. of three independent experiments, with at least seven fields scored per condition. (c) Percentage of viable motor neurons 2 weeks after exposure of organotypic cultures to lentiviral vectors. Bars represent the mean \pm s.e.m. of three independent experiments, including at least 15 spinal cord slices. The percentage is referred to control (untreated) cultures. (d) Transduction by lentiviral vectors in embryonic explants. Immunofluorescence for SMI-32, GFAP, IBA-1 and GALC (red) and eGFP fluorescence (green) allowed the identification of transduced motor neurons (MN), astroglia (Astro), microglia (Micro) and oligodendrocytes (Oligo), respectively. (e) Transduction efficiency in embryonic explants. Percentages of SMI-32, GFAP, IBA-1 or GALC-positive cells expressing eGFP are indicated. Bars represent the mean \pm s.e.m. of three independent experiments, with at least seven fields scored per condition. Scale bar in (a, d): $50 \mu \mathrm{m}$.

neuronal types and most glial cells from the spinal cord. More importantly, this work shows that both phenotypic and functional effects induced by integrating lentiviral vectors can be replicated with similar efficiency using IDLVs. The main difference was observed in purified microglial cells, where IDLVs were more toxic and less efficient (particularly regarding the expression level of eGFP) than integrating lentiviral vectors. This difference was not observed in microglia of organotypic cultures and embryonic explants, where transduction was efficient, or in vivo, where microglial transduction was rare.

Regarding cultured neuronal cells, a previous study showed no difference in transduction efficiency when retinal ganglion neurons were exposed to either IN - or IN + (class I integrase mutation D66V) feline immunodeficiency virus lentiviral vectors. ${ }^{17}$
Similarly, no difference in transduction efficiency between IN - or IN + lentiviral vectors was observed in the present work on DRG or motor neuron cultures after in vitro exposure, regardless of the protein (VSV-G or rabies-G) used for pseudotyping. VSV-Gpseudotyped vectors were more efficient compared with rabies-G vectors in DRG cultures. However, in the case of motor neuron cultures, the maximal transduction efficiency observed with VSV-Gor rabies-G-pseudotyped vectors was similar. Using VSV-Gpseudotyped vectors on postnatal organotypic cultures or embryonic explants from rat spinal cord, we observed extremely high transduction of motor neurons (c. 90\%), and efficient transduction of interneurons in the former (c. 60\%).

Of more relevance, our in vivo work shows that following direct intraspinal injection of adult animals, interneurons or motor 
a

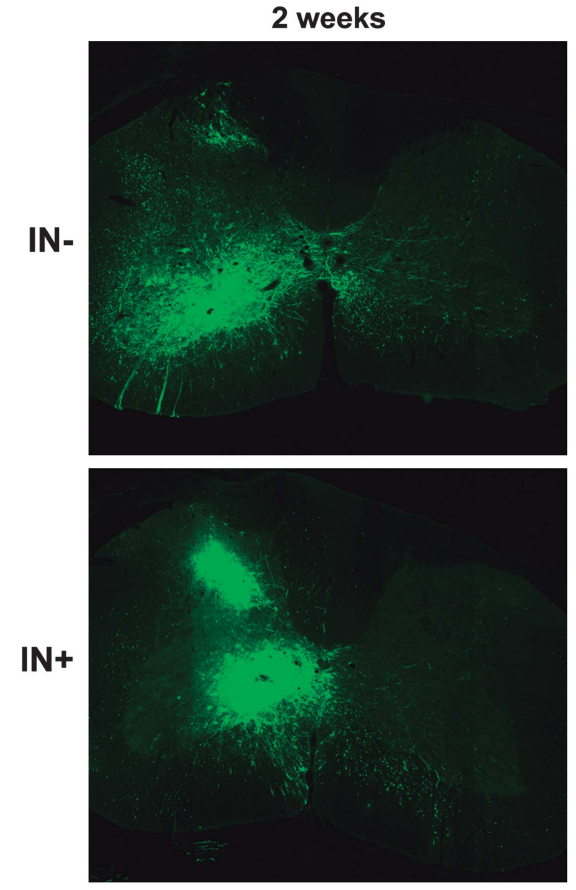

b
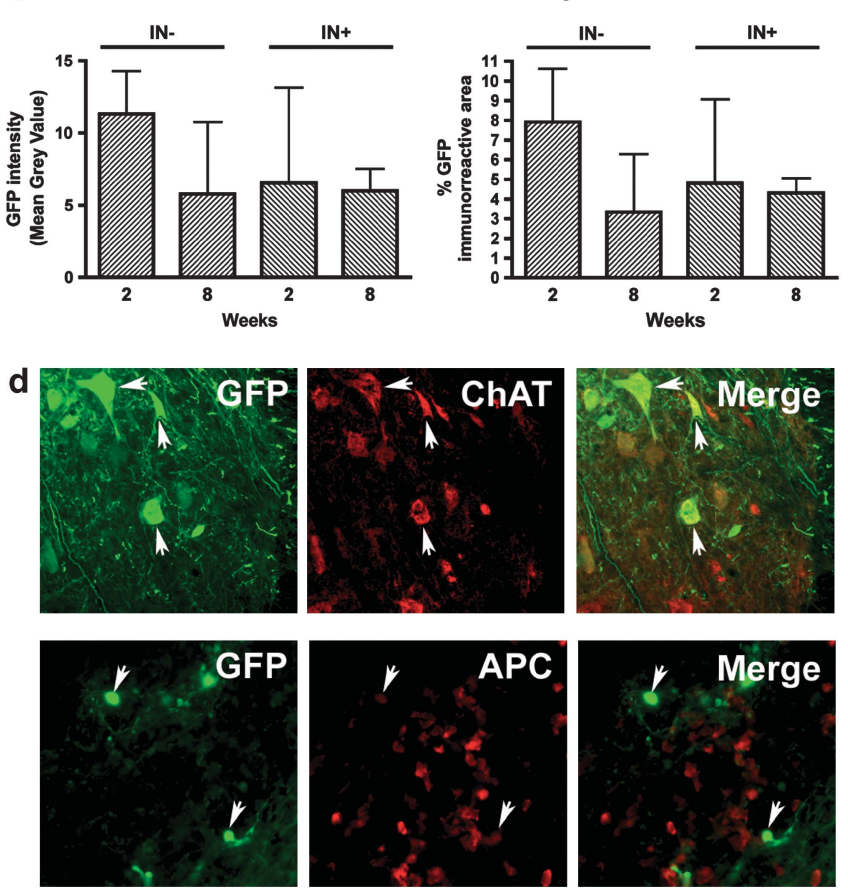

8 weeks
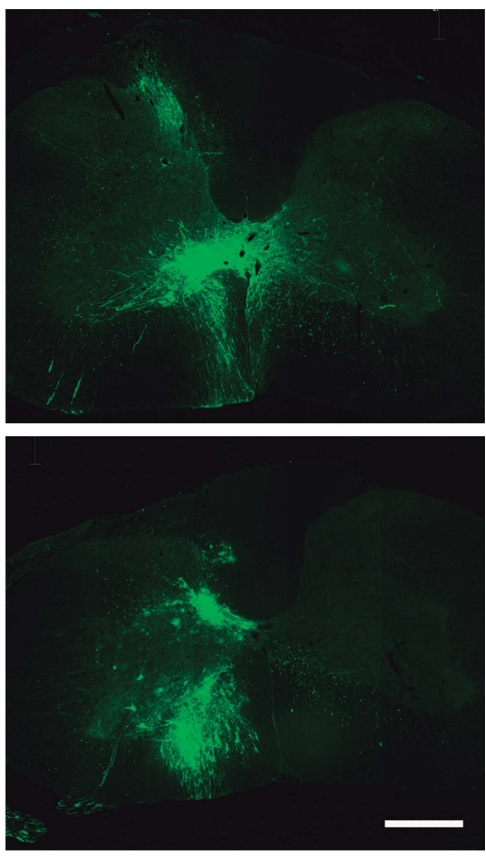

C
Neuronal transduction
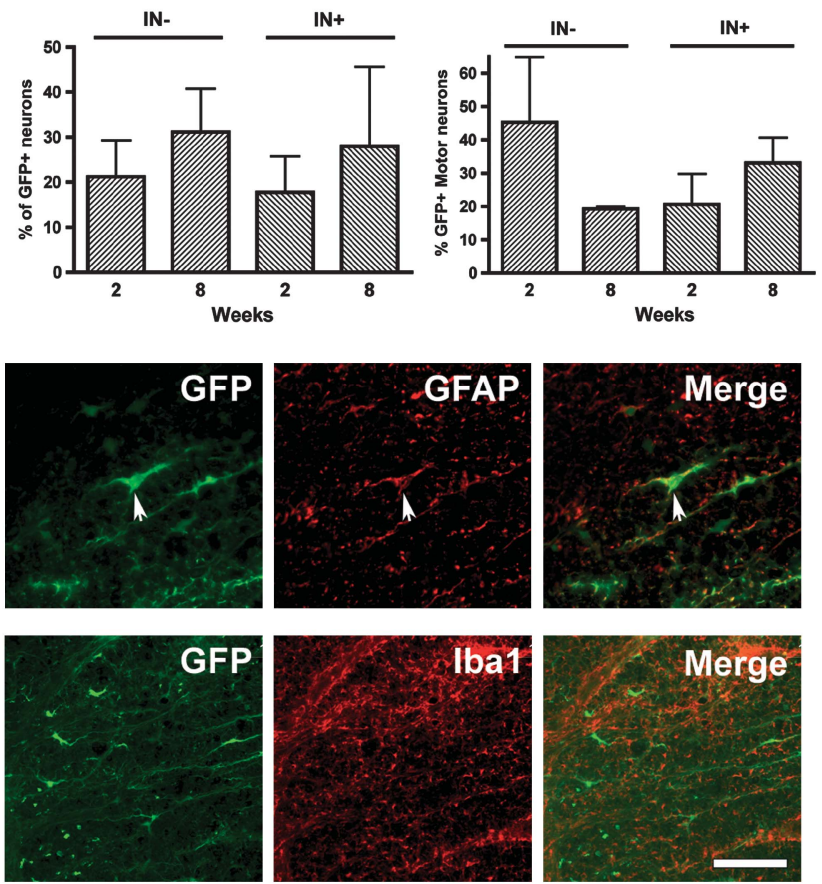

Figure 6. Transduction in rat cervical spinal cord. (a) VSV-G-pseudotyped IN - (top row) and IN + vectors (bottom row) expressing an eGFP reporter were injected into the ventral horn of the cervical enlargement of the rat spinal cord. Animals were sacrificed at 2, 4 and 8 weeks post-injection and eGFP immunostaining is shown. Scale bars: $500 \mu \mathrm{m}$. (b) Densitometric analysis of fluorescence in anti-eGFP-stained sections (left panel) and quantification of the area of eGFP immunoreactivity (right panel) did not reveal significant differences between vector forms or time points. (c) Percentages of transduced neurons (left panel) and motor neurons (right panel), determined using cell-type specific markers (NeuN as pan-neuronal and ChAT for motor neurons). (d) VSV-G-pseudotyped IN - vectors transduced a variety of cell types. Representative images show co-staining of eGFP and ChAT (motor neurons, top left panel), GFAP (astrocytes, top right panel), APC (oligodendrocytes, bottom left panel) and IBA-1 (microglia and macrophages, bottom right panel) 2 weeks post-injection. Scale bar: $100 \mu \mathrm{m}$.

neurons from rat (cervical and lumbar) and mouse (lumbar) spinal cord were transduced with similar frequencies regardless of vector integration proficiency. In agreement with previous reports, neurons were preferentially transduced with both VSV-G- and
rabies-G-pseudotyped vectors. ${ }^{1-4}$ Transduction of motor neurons in the mouse lumbar spinal cord was particularly efficient, reaching close to $60 \%$ around the injection site. It is important to note that we observed variation in both the location of gene 
a
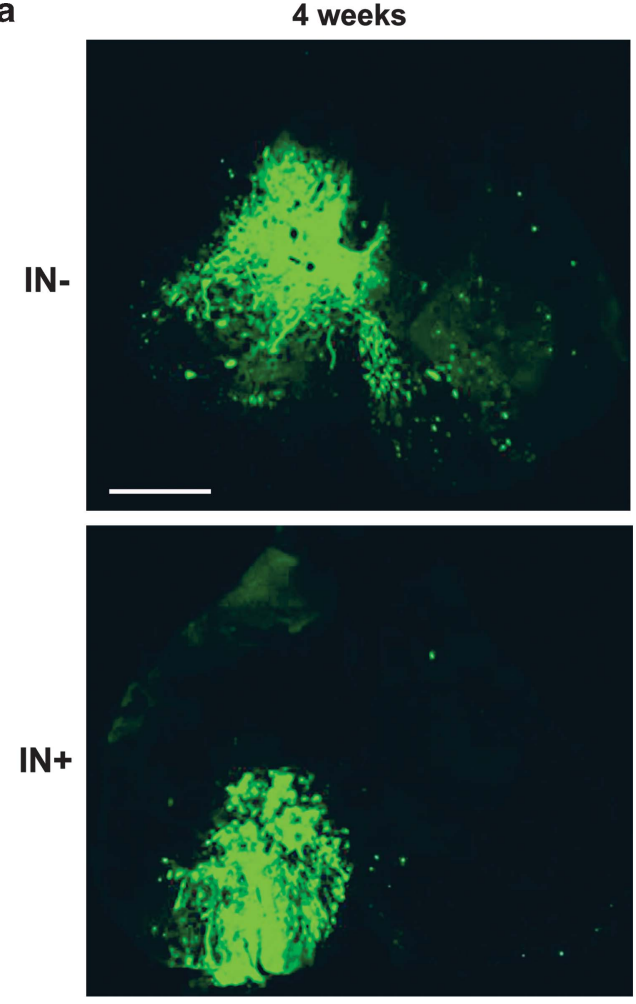

C

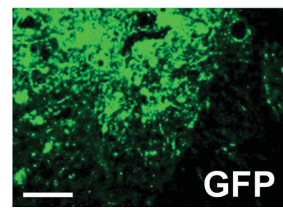

Rat neuron transduction
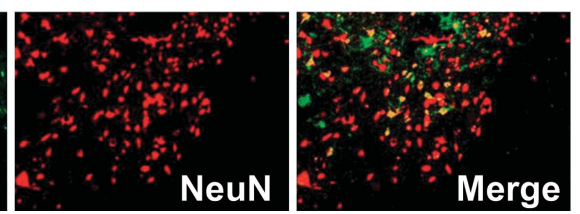

Rat neuron transduction

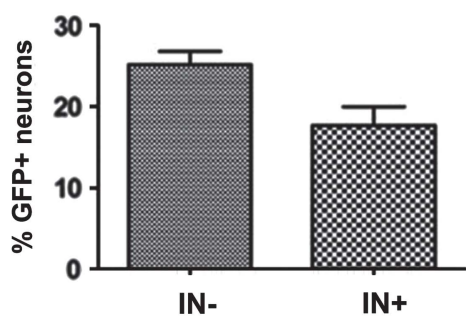

Rat motor neuron transduction

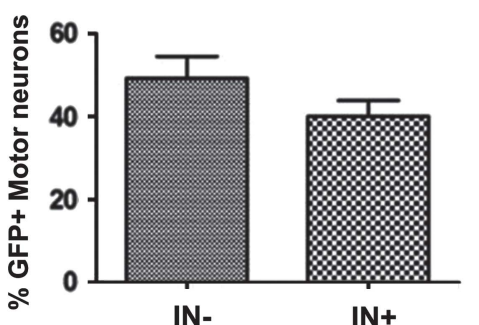

IN-

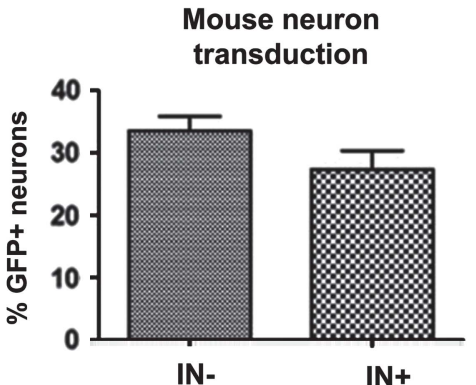

Mouse motor neuron transduction

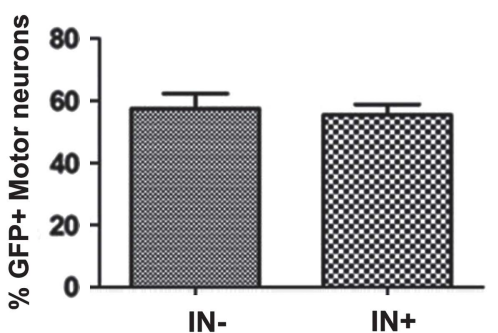

d

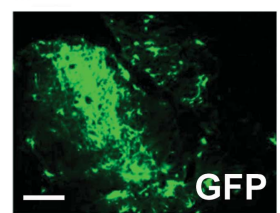

Rat astrocyte transduction

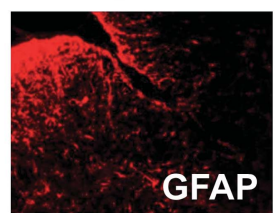

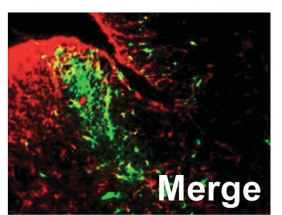

Rat oligodendrocyte transduction

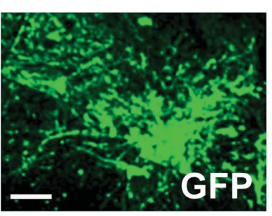

Rat motor neuron transduction
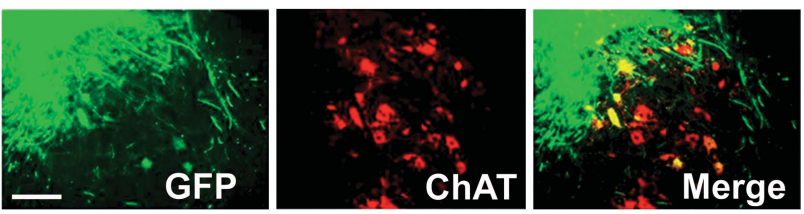

Figure 7. Transduction in rat and mice lumbar spinal cord. (a) IN - and IN + vectors efficiently express eGFP in adult rat lumbar spinal cord. Significant eGFP expression was observed at 4 weeks post-injection. (b) Transduction efficiency of IN - and IN + vectors in adult rat and mouse lumbar neurons (NeuN + cells) and motor neurons (ChAT + cells). Both vector types rendered similar percentages of NeuN-eGFP and ChAT-eGFP co-localization. (c) IN - lentivectors efficiently transduce neurons and motor neurons. Representative images of co-localization of NeuN immunoreactivity and eGFP fluorescence or ChAT immunoreactivity and eGFP fluorescence are shown. (d) IN - vector transduction of astrocytes (GFAP + cells) and oligodendrocytes (APC + cells). Scale bars: (a): $500 \mu \mathrm{m} ;(\mathrm{c}, \mathrm{d}): 100 \mu \mathrm{m}$.

marking and the efficiency of transduction, even between animals of the same group injected with the same vector stock. The use of brain atlases and coordinates is routine for stereotactic injections in the brain, ${ }^{25,26}$ particularly for small midbrain structures. However, similar resources are not available for spinal cord injections. As was the case in this study, most researchers estimate the position of the injection target site by using landmarks such as the dorsal root entry zone (if visible) or the dorsal blood vessel. Our aim was to target motor neurons located in laminae VIII and IX of the ventral horn; however, in some cases our subsequent analysis showed gene marking shifted medially towards the bordering white matter. Given the limited diffusion of the vector away from the injection site, this is likely to reflect the accuracy of the injection, and is likely to have had a negative impact on the number of transduced somata (and hence caused an underestimation of potential transduction efficiency). These results underscore the need for better specificity to target isolated laminae, given that populations of spinal neurons with distinct functional properties are often distributed in a highly restricted manner. One potential solution to this problem is to use motorized stereotaxic frames to precisely set the position of the micropipette. Differences in the extent or volume of the transduced area are most likely to be due to problems with the micropipette, specifically clogging or backflow along the needle tract. ${ }^{27}$ The glass micropipettes used for the vector injections in this study were first 'pulled' using a standard pipette puller. The 
tips were then clipped using a pair of forceps to give a bore small enough to minimize tissue damage but wide enough to prevent clogging. The latter step was carried out by hand and is subject to human error. These factors should be taken into account for the delivery of lentiviral vectors and other therapeutics in different experimental or therapeutic paradigms.

Cultured astrocytes were transduced with extremely high efficiency (around 50\% at MOI 1, >90\% at MOI 10) by IN - and IN + VSV-G vectors. Although no significant difference was noted in the percentage of transduced cells, the intensity of eGFP fluorescence was somewhat lower with the former. Cultured astrocytes have a high proliferation rate, and it has been reported that expression levels from IDLVs are lower than those from integrating lentiviral vectors in dividing cells (see ref. ${ }^{16}$ for a review). Lower eGFP production per cell from IN - vectors in this culture system is therefore not unexpected. Transduction of astrocytes in organotypic cultures was extremely efficient (c. $90 \%$ ), while it was efficient but somewhat lower in embryonic explants (c. 60\%), again regardless of vector integration proficiency. In contrast to this highly efficient transduction in culture systems, in vivo vector injections showed that astrocytes were transduced at comparatively low levels with respect to neurons, even though they were the glial lineage most frequently transduced, and again no vector integration-related differences were observed. Oligodendrocytes were transduced at intermediate levels (c. 50\%) in embryonic explants, and some transduction was noted in mixed glial cell cultures and after direct cord injections in vivo, irrespective of vector integration.

The one system in which differential efficiency of IN - and IN + vectors was noted is purified microglia. In these cultured cells IN vectors led to somewhat reduced percentages of transduction, but also to particularly low production of eGFP in transduced cells. A more pronounced trend to reduced microglial viability was also observed with IN - vectors. A number of factors may contribute to explaining the disparity. It is possible that the absence of vpr in the third-generation lentivector system used in the current study is particularly deleterious for IDLV transduction of purified microglia. Together with matrix protein and central polypurine tract, vpr and integrase participate in HIV nuclear import. ${ }^{28-32}$ Deletion of the $v p r$ gene causes a $50 \%$ reduction of lentiviral vector delivery to macrophages, ${ }^{1,2}$ suggesting the existence of specific requirements or barriers in differentiated macrophages regarding lentiviral vector transduction. Albeit the D64V integrase mutation used here is expected to affect only catalytic activity and not nuclear import, in the absence of vpr it may have a differential effect on microglia transduction. It is also possible that, in common with other proliferating cells, expression from IDLVs in the slowly dividing purified microglia is not as efficient as that from IN + vectors. ${ }^{16}$ In sharp contrast with purified microglia, no difference was observed in transduction efficiency between IDLVs and integrating lentivectors for microglia in postnatal organotypic cultures (c. 60\%) and embryonic explants (c. 90\%), where no obvious toxicity was noted. The difference in toxicity of IN - and $\mathrm{IN}+$ vectors on isolated microglial cells versus microglia in organotypic cultures could be explained by the enhanced trophic support for microglial cells in the latter system, as for instance astrocytes secrete granulocyte-macrophage colonystimulating factor. ${ }^{33}$ Of more importance, few microglial cells were transduced in vivo. We observed some microglial reactivity along the needle tract following lentiviral injection into the spinal cord, but no difference related to vector integration potential. Similar observations have been made after injection of lentiviral vector into the rat striatum and cortex. ${ }^{4,34}$

Both IN - and IN + lentiviral vectors showed some toxicity towards cultured cells at increased vector doses, particularly for microglia but also for cultured astrocytes and motor neurons. Several proteins of HIV-1 like tat and gp120 have been shown to be toxic to cells of the CNS, ${ }^{35}$ but those proteins are not included in the third-generation lentiviral vector system used in the current study. Injection of a chimeric HIV-1 env-gag fusion protein (consisting of 81 aa from gp41-env and 190 aa from p24-gag) increased excitotoxic damage to the $\mathrm{CNS}^{36}$ implying that gag could play a role in neurotoxicity. The lentiviral vector concentration protocol used in the current study includes highspeed centrifugation, which leads to the presence of other possibly immunoreactive molecules in the final vector stock, for instance serum components. ${ }^{37}$ Further experiments will be required to determine whether the vector itself and/or other contaminants are responsible for the observed toxicity, but at least in the case of cultured microglia the increased toxic effect of IDLVs points to some vector involvement. The causes of this increased toxicity were not investigated here, but it could be hypothesized that elevated levels of episomal vector DNA from IDLVs may somehow lead to reduced viability. We have observed increased expression of some interferon-inducible genes and reduced viability in postnatal cerebellar granule neurons transduced with high IDLV doses, and also at low doses if the vectors encoded shRNA, but standard integrating lentivectors were not tested in that study so it is unclear whether the effect is specific to IDLVs. ${ }^{38}$

We have shown using cultured cells, organotypic systems and in vivo injections that a marker gene can be very efficiently expressed from IDLVs in the spinal cord. However, proficiency for induction of a biological effect after the overexpression or downregulation of a selected gene is a key feature that has to be demonstrated for experimental or therapeutic purposes. Here, we have shown two functional effects mediated by IN - vectors as efficiently as IN + lentiviral vectors: (i) trophic support for cultured motor neurons provided by transgenic Gdnf overexpression and (ii) down-regulation of Trpv1 expression in DRG neurons through shRNAs. These data indicate that IDLVs are able to mediate functional effects in nervous system cells of relevance to human disease, as efficiently as standard integrating vectors. Given the highly reduced risk of insertional mutagenesis of IDLVs, our findings are likely to have important implications for lentiviral gene therapy in the spinal cord.

\section{MATERIALS AND METHODS}

\section{Plasmids}

The lentiviral plasmid encoding eGFP was pRRLsin_PPT_CMV_GFPpre, a kind gift from Luigi Naldini (Milan, Italy). ${ }^{31,39}$ This self-inactivating lentiviral construct contains a CMV promoter driving eGFP expression, followed by the Woodchuck hepatitis virus post-transcriptional regulatory element (WPRE). pcDNA 3 plasmids encoding rat Gdnf precursor (pGdnf, GenBank NM_019139.1) and mature Gdnf (mGdnf, including a Met residue followed by Ser-78 to the end of Gdnf encoded by above GenBank sequence) were a kind gift of Rosario Osta (Zaragoza, Spain). The lentiviral transfer plasmids encoding pGdnf and mGdnf were produced by subcloning of the corresponding CDNA into pRRLsc_CMV_eleGFP_W, using BamHI and Nhel/BamHI, respectively. This lentiviral construct contains a CMV promoter driving transgene expression, followed by an internal ribosomal entry site-eGFP cassette and the WPRE.

The lentiviral shRNA expression plasmid was generated by cloning the PCR-amplified human $\mathrm{H} 1$ promoter from pSUPER_gfp_neo into pRRLsin PPT CMV GFPpre using EcoRI and Acc65l, downstream of WPRE. The PCR primers added two unique restriction sites (Mlul and Xmal) downstream of the $\mathrm{H} 1$ promoter. The different shRNA sequences were then cloned using the Mlul and Xmal restriction sites. Three different Trpv1 shRNAs named TRPsh1, TRPsh2 and TRPsh3 were designed. TRPsh1 and TRPsh2 were selected using the Dharmacon siDESIGN center algorithm (OligoEngine, Seattle, USA); TRPsh3 was designed by Gillian McFeat (Pfizer, Havant, UK) using BD Clontech's RNAi designer (Mountain View, CA, USA) Each shRNA consisted of 19-mer sense and antisense components, separated by a non-complementary spacer sequence (TTCAAGAGA) predicted to form a hairpin. The antisense sequence was immediately followed by a run of five thymidines that comprise the RNA pol III termination signal. The antisense sequences, designed to target different parts of rat Trpv1 (GenBank NM_031982), were as follows: TRPsh1-TCTITGAACTCGCTGTCAG; TRPsh2-TAGTAGAGCATGTTGGTCC; and TRPsh3-GATGGTGTCATTCTGCCCA. 
Lentiviral vector production

Third-generation self-inactivating HIV-1-based vectors were produced by transient co-transfection of four plasmids in 293T cells as we have previously described. ${ }^{22}$ The transfer plasmids (containing the cassette to be incorporated in the virus particles) were based on the SIN-18 pRRL backbone, which incorporates minimal HIV elements and produces selfinactivating (SIN) vectors through $3^{\prime}$-LTR truncation. ${ }^{39}$ The packaging plasmids were pRSV-rev and pMDLg/pRRE (integration-proficient, IN $+i^{40}$ ) or pMDLg/pRREintD64V (integration-deficient, $I N-; 22$ ). Vectors were pseudotyped with either a standard vesicular stomatitis virus $G$ glycoprotein (VSV-G; plasmid pMD2.G) or rabies virus envelope glycoprotein (plasmid pHCMV.rabies $\mathrm{G}^{41}{ }^{41}$ ). Vectors were concentrated by ultracentrifugation and titrated using standard methods. ${ }^{22}$

\section{Cell cultures}

Culture media and sera were purchased from Invitrogen (San Diego, CA, USA) and all other reagents were from Sigma-Aldrich (St Louis, MO, USA) unless otherwise stated. We cultured HeLa and HEK293T cells in DMEM with standard supplements.

Spinal motor neuron cultures were produced from E14-15 Wistar rat embryos as described. ${ }^{42}$ This method uses several steps for motor neuron purification including dissection, OPTIPREP cushion centrifugation and immunopanning with $\mathrm{p} 75^{\mathrm{LNTR}}$ antibodies, rendering essentially pure cultures. Motor neurons were plated at a density of $2220 \mathrm{cells}^{\mathrm{cm}} \mathrm{cm}^{-2}$ on laminin/polyornithine covered wells in Neurobasal medium supplemented with B27 (Invitrogen), 2\% horse serum, $0.5 \mathrm{~mm}$ L-glutamine, $25 \mu \mathrm{m} \mathrm{2-}$ mercaptoethanol, $25 \mu \mathrm{m}$ L-glutamate, and $1 \mathrm{ng} \mathrm{ml}^{-1} \mathrm{BDNF}$, and after $2 \mathrm{~h}$ the vectors were added and the cultures were incubated for 3 days. For the Gdnf overexpression experiments, a similar protocol was performed but, after 3 days in culture, half of the medium was changed three times to remove $\mathrm{BDNF}$, and the neurons were incubated for 3 additional days in the same medium without L-glutamate or BDNF. Motor neurons with refringent soma and neurites longer than four soma diameters were considered viable.

Primary spinal cord mixed glial cultures and highly enriched astrocyte or microglial cultures were prepared from 1 to 2-day-old Wistar rat pups (both sexes) according to the procedures of Saneto and De Vellis. ${ }^{43}$ Astrocyte cultures were obtained by the shaking method ${ }^{43}$ combined with incubation with cytosine arabinoside as described. ${ }^{44}$ The $80 \%$ confluent cultures used for the experiments were highly enriched in GFAPimmunoreactive cells (95\% purity) with only $0.5-1 \%$ of the culture positive for the CD11b microglial marker. Microglia from the top of the mixed glial cultures were obtained using the shaking method ${ }^{43}$ followed by $30 \mathrm{~min}$ incubation in a bacteriological Petri dish to eliminate nonattaching oligodendrocytes. Microglia from below the astrocyte monolayer of mixed glial cultures were obtained using the method of mild trypsinization. ${ }^{45}$ Both types of microglia were combined and the cultures obtained showed $98 \%$ CD11b-positive cells. Microglial cultures were maintained in a 1:1 mixture of fresh and mixed glial culture-preconditioned DMEM supplemented with $10 \% \mathrm{FBS}, 100 \mathrm{IU} \mathrm{ml}^{-1}$ penicillin and $100 \mu \mathrm{g} \mathrm{ml}^{-1}$ streptomycin. Microglia and astrocyte viability were measured using the spectrophotometric 3-[4,5-dimethylthiazol-2-yl]-2,5dephenyl tetra-zolium bromide (MTT) assay by incubating cultures for $2 \mathrm{~h}$ at $37^{\circ} \mathrm{C}$ with $5 \% \mathrm{CO}_{2}$ and $0.5 \mathrm{mg} \mathrm{ml}^{-1} \mathrm{MTT}$. Cells were then lysed in dimethylsulfoxide and MTT product (colored formazan) was measured by absorbance at $570 \mathrm{~nm}$. For transduction experiments, microglial cells or

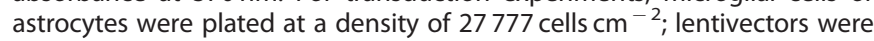
added $24 \mathrm{~h}$ later, and the cultures were incubated for 3 additional days.

DRG neurons were obtained from terminally anaesthetized adult Wistar rats (150-200 g). DRGs were removed from all spinal levels. Ganglia were microdissected and then incubated in $0.125 \%$ collagenase (Sigma, Gillingham, UK) for $2 \mathrm{~h}$ at $37^{\circ} \mathrm{C}$ and $5 \% \mathrm{CO}_{2}$ in a humidified incubator. Coverslips pre-coated with $0.01 \%$ poly-L-Lysine (Sigma) were incubated for $2 \mathrm{~h}$ in $10 \mu \mathrm{g} \mathrm{ml}^{-1}$ Engelbreth-Holm Swarm (EHS) laminin (Sigma) in 24-well plates (Nunc, Roskilde, Denmark). After collagenase treatment the ganglia were washed briefly in F12 medium (Invitrogen, Paisley, UK). The ganglia were dissociated mechanically in $500 \mu \mathrm{l}$ of F12 medium using a Gilson P1000 (the tip of the pipette was cut in order to enlarge the bore). A cushion gradient was made up by carefully mixing $1 \mathrm{ml}$ of $\mathrm{F} 12$ medium and $1 \mathrm{ml}$ of albumin solution from bovine serum (Sigma) in a 15-ml Falcon. The dissociated cell suspension was carefully placed on top of the cushion gradient and the tube was centrifuged at $58 \mathrm{~g}$ in a microcentrifuge (PK110 ALC, Milano, Italy) for $8 \mathrm{~min}$. The supernatant was removed and placed in a fresh tube while $100 \mu \mathrm{l}$ of calcium- and magnesium-free Hank's balanced salts solution (Invitrogen,
UK) containing $50 \mu \mathrm{g} \mathrm{ml}^{-1}$ DNase Type I (Sigma) and $250 \mu \mathrm{g} \mathrm{ml}^{-1}$ soybean trypsin inhibitor Type II (Sigma) was used to re-suspend the pellet. Any remaining cells in the supernatant were collected by centrifugation at 100 for $6 \mathrm{~min}$ on top of another cushion gradient. Purified DRG neuron preparations were mixed with either IN + or IN - vector forms and then resuspended in modified Bottenstein and Sato's medium (1\% N2supplement (Invitrogen, UK), $1 \%$ bovine albumin fraction $\mathrm{V}$ solution (Sigma), 100 units ml ${ }^{-1}$ penicillin and $100 \mu \mathrm{g} \mathrm{ml}^{-1}$ streptomycin (Invitrogen, UK), $10 \mathrm{ng} \mathrm{ml}^{-1} \mathrm{NGF}$ ). The cells were seeded on coverslips pre-coated with $0.01 \%$ poly-L-lysine and $10 \mu \mathrm{g} \mathrm{ml}^{-1}$ EHS laminin at a density of $1 \times 10^{3}$ cells per well. Untreated neurons were used as a control. Neurons were maintained in a humidified cabinet incubator at $5 \% \mathrm{CO}_{2}$ and $37^{\circ} \mathrm{C}$. At 2, 4 and 8 days post-transduction, the cultures were washed with sterile PBS (phosphate-buffered saline) and fixed for $15 \mathrm{~min}$ with freshly prepared $4 \%$ paraformaldehyde. Cells were permeabilized with $100 \%$ methanol for $1 \mathrm{~min}$ at $-20^{\circ} \mathrm{C}$.

\section{Organotypic cultures and explants}

Postnatal rat spinal cord organotypic cultures were prepared from lumbar spinal cords of 8-day-old rat pups (P8), as previously described. ${ }^{23}$ Briefly, lumbar spinal cords were collected under sterile conditions and transferred to sterile Gey's balanced salt solution, containing glucose $\left(6.4 \mathrm{mg} \mathrm{ml}^{-1}\right)$. They were transversely sectioned into $350 \mu \mathrm{m}$ slices with a Mcllwain Tissue Chopper (Gomshall, Surrey, UK). Sections were carefully placed on Millipore Millicell-CM porous membranes $(0.4 \mu \mathrm{m})$ (Millipore, Billerica, MA, USA) in $35-\mathrm{mm}$ culture wells containing $1 \mathrm{ml}$ of incubation media (50\% MEM, $25 \mathrm{mM}$ Hepes, $25 \%$ heat-inactivated horse serum, $2 \mathrm{~mm}$ glutamine and $25 \%$ Hanks' balanced salt solution (Invitrogen, Carlsbad, CA, USA) supplemented with D-glucose $\left(25.6 \mathrm{mg} \mathrm{ml}^{-1}\right)$; final $\mathrm{pH}$ 7.2). Cultures were incubated at $37^{\circ} \mathrm{C}$ in a $5 \% \mathrm{CO}_{2} / 95 \%$ air humidified environment. Under these conditions, cultures can be maintained up to 3 months with stable motor neuron survival and preservation of synaptic morphology. Cultures were let to stabilize for 1 week, after which $1.5 \mu \mathrm{l}(4.9 \times 10 \mathrm{e} 7$ eGFP transducing units (TU) $\mathrm{ml}^{-1}$ ) of lentiviral vector stock was added on top of each explants, and medium was replaced every 3 days. After 15 days, which was the optimum time for cell transduction in these cultures, explants were fixed with $4 \%$ paraformaldehyde in phosphate buffer.

Embryonic explant cultures were prepared from E15-E16 fetuses removed by cesarean section from pregnant Sprague-Dawley rats as previously described. ${ }^{24}$ Lumbar spinal cords were dissected from each embryo with forceps, transferred to ice-cold L15 medium and the meninges and ganglia carefully removed. Cords were transversely sectioned into $350 \mu \mathrm{m}$ slices. Sections were placed at a density of 20 sections per well on $35-\mathrm{mm}$ wells pre-coated with poly-DL-ornithine $\left(30 \mu \mathrm{g} \mathrm{ml}^{-1}\right)$ and L-laminin $\left(2 \mu \mathrm{g} \mathrm{ml}^{-1}\right)$, and containing $2 \mathrm{ml}$ of MEM supplemented with $5 \%$ heat-inactivated horse serum, $5 \%$ fetal bovine serum, $2 \mathrm{mM}$ glutamine, $0.6 \%$ glucose and $15 \mu \mathrm{g} \mathrm{ml}^{-1}$ gentamicin. Explants were maintained at $37^{\circ} \mathrm{C}$ under a humidified $5 \% \quad \mathrm{CO}_{2}$ atmosphere. Cells were let to migrate outside the cord for 10 days and after this period of time, they were exposed to lentiviral vector $(7 \times 10 \mathrm{e} 5$ eGFP TU ml ${ }^{-1}$ ). Three days later, the medium was replaced. Tissue was fixed with $4 \%$ paraformaldehyde in phosphate buffer 14 days posttransduction.

\section{In vivo injections and histology}

Viral delivery into the adult rat cervical or lumbar spinal cord and mouse lumbar spinal cord was carried out under provisions of the UK Animals (Scientific Procedures) Act 1986 similarly to previously published. ${ }^{6}$ Under ketamine and medetomidine anesthesia, the spinal cord in adult Wistar rats or CD1 mice was exposed by hemi-laminectomy. In all, $2 \mu$ l of lentiviral vector stock (IN $-4.74 \times 10^{5}$ eGFP TU, IN $\left.+3.64 \times 10^{5} \mathrm{TU}\right)$ per site was infused unilaterally into three sites along the cervical or lumbar enlargement at a rate of $0.2 \mu \mathrm{l}$ per minute via a finely drawn glass micropipette connected to a microinfusion pump. Once microinjections were completed, the animal was sutured up and Atipamezole was administered to speed recovery from anesthesia. 2, 4 and 8 weeks postinjection for rat cervical injection, or 1 month post-injection for rat and mouse lumbar injection, randomly selected animals were terminally anaesthetized by intraperitoneal injection of sodium pentobarbital and transcardially perfused with $4 \%$ paraformaldehyde. Spinal cords and attached DRGs were removed, post-fixed for $24 \mathrm{~h}$ at $4{ }^{\circ} \mathrm{C}$ and then cryoprotected in $30 \%$ sucrose for $2-3$ days at $4{ }^{\circ} \mathrm{C}$. Cords were blocked and frozen in OCT (BDH, London, UK). Twenty-micrometer coronal sections were cut on a cryostat and mounted on superfrost slides (BDH). 
Immunohistochemistry

Standard protocols were used. Primary antibodies: mouse anti- $\beta$-(III)tubulin (Promega, Madison, WI, USA; Cat. G7121, 1:1000), goat anti-TRPV1 (Neuromics, Edina, MN, USA; Cat. GT15129, 1:1000), mouse anti-SMI-32 (Abcam plc, Cambridge, MA, USA; Cat. 73273, 1:1000), rabbit anti-MAP-2 (Chemicon, Billerica, MA, USA; Cat. AB5622, 1:1000), mouse anti-GalC (Millipore MAB342, 1:500), goat anti-ChAT (Chemicon AB 144P, 1:50), mouse anti-NeuN (Chemicon MAB 377, 1:500), rabbit anti-GFAP (Dakopatts, Glostrup, Denmark; Cat. Z-0334, 1:500), rabbit anti-IBA-1 (WAKO, Osaka, Japan; Cat. 019-19741, 1:1000), mouse anti-APC (Calbiochem, Darmstadt, Germany; Cat. OP80 Ab-7, 1:500), rabbit anti-eGFP (Invitrogen, A11122, 1:1000) and mouse anti-eGFP (UC Davis/NINDS NeuroLab Facility, clone N86/38, 1:1000) were used in blocking solution (PBS $+10 \%$ goat serum $+1 \%$ Triton X100)

\section{eGFP densitometry and neuron cell counts}

For estimates of in vitro transduction, six random fields of view per condition were captured using a Zeiss Axio Imager.Z1 fluorescent microscope (Zeiss, Cambridge, UK). To quantify the level of native eGFP production, fluorescence levels for each cell soma were measured as mean pixel density (gray levels) using AxioVision 4.6 image analysis software (Zeiss). In vivo eGFP fluorescence intensity was measured in eGFP immunohistochemistry-processed sections, using the mean intensity of three sections per animal, with the mean gray value and the percentage of immunoreactive area being obtained from $1500 \times 2250 \mu \mathrm{m}$ microphotographs using AxioVision 4.6 image analysis software (Zeiss). The quantification of percentages of in vivo neuronal transduction was performed in three coronal microphotographs per animal, processed for double immunohistochemistry for GFP and NeuN or ChAT and showing the entire ventral horn at the relevant level, analyzed at high magnification for accurate cell-type identification.

\section{Data analysis}

All in vitro experiments were performed at least three times (different primary cultures), each including duplicate or triplicate samples. The $n$ for the in vivo experiments is indicated in the corresponding figure legend. All results are expressed as mean \pm standard error of the mean. One-way analysis of variance followed by Tukey's Multiple Comparison post hoc test was used to determine significant differences $(P<0.05)$ for normally distributed samples. For samples with non-normal distribution, nonparametric Kruskal-Wallis test was performed followed by Dunn's multiple comparison test to determine significant differences between groups $(P<0.05)$.

\section{CONFLICT OF INTEREST}

The authors declare no conflict of interest.

\section{ACKNOWLEDGEMENTS}

We thank Luigi Naldini, Miguel Sena-Esteves and Rosario Osta for lentiviral, rabies envelope and Gdnf plasmids, respectively. We acknowledge Genoma España (GENAME project), the 7th EU Framework Program (PERSIST project, Grant agreement 222878), The Friends of Guy's Hospital and Comisión de Investigación Científica (CSIC) de la UDELAR for financial support. SGA and VC were supported by PhD Studentships from the Egyptian Government and the 'Govern Balear, Conselleria d'Innovació', respectively.

\section{AUTHOR CONTRIBUTIONS}

RJY-M conceived the project; HP, EF, SBM, LM, GO, JL and RJY-M contributed to experimental design; $\mathrm{HP}, \mathrm{EF}, \mathrm{SGA}, \mathrm{NL}, \mathrm{THH}, \mathrm{PY}, \mathrm{KW}$ and $\mathrm{VC}-\mathrm{M}$ conducted the experimental work; HP, EF and RJY-M wrote the manuscript, and all authors contributed to data analysis and commented on the manuscript.

\section{REFERENCES}

1 Naldini L, Blömer U, Gallay P, Ory D, Mulligan R, Gage FH et al. In vivo gene delivery and stable transduction of nondividing cells by a lentiviral vector. Science 1996; 272: 263-267.

2 Zufferey R, Nagy D, Mandel RJ, Naldini L, Trono D. Multiply attenuated lentiviral vector achieves efficient gene delivery in vivo. Nat Biotechnol 1997; 15: 871-875.
3 Blömer U, Naldini L, Kafri T, Trono D, Verma IM, Gage FH. Highly efficient and sustained gene transfer in adult neurons with a lentivirus vector. $J$ Virol 1997; 71: 6641-6649.

4 Rahim AA, Wong AM, Howe SJ, Buckley SM, Acosta-Saltos AD, Elston KE et al. Efficient gene delivery to the adult and fetal CNS using pseudotyped nonintegrating lentiviral vectors. Gene Ther 2009; 16: 509-520.

5 Jakobsson J, Lundberg C. Lentiviral vectors for use in the central nervous system. Mol Ther 2006; 13: 484-493.

6 Wong LF, Yip PK, Battaglia A, Grist J, Corcoran J, Maden M et al. Retinoic acid receptor beta2 promotes functional regeneration of sensory axons in the spinal cord. Nat Neurosci 2006; 9: 243-250.

7 Wong LF, Goodhead L, Prat C, Mitrophanous KA, Kingsman SM, Mazarakis ND. Lentivirus-mediated gene transfer to the central nervous system: therapeutic and research applications. Hum Gene Ther 2006; 17: 1-9.

8 Ralph GS, Radcliffe PA, Day DM, Carthy JM, Leroux MA, Lee DC et al. Silencing mutant SOD1 using RNAi protects against neurodegeneration and extends survival in an ALS model. Nat Med 2005; 11: 429-433.

9 Raoul C, Abbas-Terki T, Bensadoun JC, Guillot S, Haase G, Szulc J et al. Lentiviralmediated silencing of SOD1 through RNA interference retards disease onset and progression in a mouse model of ALS. Nat Med 2005; 11: 423-428.

10 Yip PK, Wong LF, Pattinson D, Battaglia A, Grist J, Bradbury EJ et al. Lentiviral vector expressing retinoic acid receptor beta2 promotes recovery of function after corticospinal tract injury in the adult rat spinal cord. Hum Mol Genet 2006; 15: $3107-3118$

11 Levine BL, Humeau LM, Boyer J, MacGregor RR, Rebello T, Lu X et al. Gene transfer in humans using a conditionally replicating lentiviral vector. Proc Natl Acad Sci USA 2006; 103: 17372-17377.

12 Cartier N, Hacein-Bey-Abina S, Bartholomae CC, Veres G, Schmidt M, Kutschera et al. Hematopoietic stem cell gene therapy with a lentiviral vector in X-linked adrenoleukodystrophy. Science 2009; 326: 818-823.

13 Baum C, Düllmann J, Li Z, Fehse B, Meyer J, Williams DA et al. Side effects of retroviral gene transfer into hematopoietic stem cells. Blood 2003; 101: 2099-2114.

14 Leavitt AD, Robles G, Alesandro N, Varmus HE. Human immunodeficiency virus type 1 integrase mutants retain in vitro integrase activity yet fail to integrate viral DNA efficiently during infection. J Virol 1996; 70: 721-728.

15 Engelman A. In vivo analysis of retroviral integrase structure and function. Adv Virus Res 1999; 52: 411-426.

16 Wanisch K, Yáñez-Muñoz RJ. Integration-deficient lentiviral vectors: a slow coming of age. Mol Ther 2009; 17: 1316-1332.

17 Saenz DT, Loewen N, Peretz M, Whitwam T, Barraza R, Howell KG et al. Unintegrated lentivirus DNA persistence and accessibility to expression in nondividing cells: analysis with class I integrase mutants. J Virol 2004; 78: 2906-2920.

18 Vargas JJ, Gusella GL, Najfeld V, Klotman ME, Cara A. Novel integrase-defective lentiviral episomal vectors for gene transfer. Hum Gene Ther 2004; 15: 361-372.

19 Lu R, Nakajima N, Hofmann W, Benkirane M, Jeang KT, Sodroski J et al. Simian virus 40-based replication of catalytically inactive human immunodeficiency virus type 1 integrase mutants in nonpermissive $T$ cells and monocyte-derived macrophages. J Virol 2004; 78: 658-668.

20 Apolonia L, Waddington SN, Fernandes C, Ward NJ, Bouma G, Blundell MP et al. Stable gene transfer to muscle using non-integrating lentiviral vectors. Mol Ther 2007: 15: 1947-1954.

21 Philippe S, Sarkis C, Barkats M, Mammeri H, Ladroue C, Petit C et al. Lentiviral vectors with a defective integrase allow efficient and sustained transgene expression in vitro and in vivo. Proc Natl Acad Sci USA 2006; 103: 17684-17689.

22 Yáñez-Muñoz RJ, Balaggan KS, Macneil A, Howe SJ, Schmidt M, Smith AJ et al. Effective gene therapy with nonintegrating lentiviral vectors. Nat Med 2006; 12: 348-353.

23 Tolosa L, Mir M, Asensio VJ, Olmos G, Llado J. Vascular endothelial growth factor protects spinal cord motoneurons against glutamate-induced excitotoxicity via phosphatidylinositol 3-kinase. J Neurochem 2008; 105: 1080-1090.

24 Mir M, Asensio VJ, Tolosa L, Gou-Fabregas M, Soler RM, Llado J et al. Tumor necrosis factor alpha and interferon gamma cooperatively induce oxidative stress and motoneuron death in rat spinal cord embryonic explants. Neuroscience 2009; 162: 959-971.

25 Paxinos G, Franklin K. The Mouse Brain in Stereotaxic Coordinates. 3rd edn Elsevier: Amsterdam, Netherlands, 2007.

26 Paxinos G, Watson C. The Rat Brain in Stereotaxic Coordinates. 6th edn Elsevier: Amsterdam, Netherlands, 2006

27 Cetin A, Komai S, Eliava M, Seeburg PH, Osten P. Stereotaxic gene delivery in the rodent brain. Nat Protoc 2006; 1: 3166-3173.

28 Heinzinger NK, Bukinsky MI, Haggerty SA, Ragland AM, Kewalramani V, Lee MA et al. The Vpr protein of human immunodeficiency virus type 1 influences nuclear localization of viral nucleic acids in nondividing host cells. Proc Natl Acad Sci USA 1994; 91: 7311-7315. 
29 Gallay P, Hope T, Chin D, Trono D. HIV-1 infection of nondividing cells through the recognition of integrase by the importin/karyopherin pathway. Proc Natl Acad Sci USA 1997; 94: 9825-9830.

30 Bukrinsky MI, Haggerty S, Dempsey MP, Sharova N, Adzhubel A, Spitz L et al. A nuclear localization signal within HIV-1 matrix protein that governs infection of non-dividing cells. Nature 1993; 365: 666-669.

31 Follenzi A, Ailles LE, Bakovic S, Geuna M, Naldini L. Gene transfer by lentiviral vectors is limited by nuclear translocation and rescued by HIV-1 pol sequences. Nat Genet 2000; 25: 217-222.

32 Zennou V, Petit C, Guetard D, Nerhbass U, Montagnier L, Charneau P. HIV-1 genome nuclear import is mediated by a central DNA flap. Cell 2000; 101: 173-185.

33 Malipiero UV, Frei K, Fontana A. Production of hemopoietic colony-stimulating factors by astrocytes. J Immunol 1990; 144: 3816-3821.

34 Hutson TH, Verhaagen J, Yáñez-Muñoz RJ, Moon LD. Corticospinal tract transduction: a comparison of seven adeno-associated viral vector serotypes and a non-integrating lentiviral vector. Gene Ther 2012; 19: 49-60.

35 Sabatier J, Vives E, Mabrouk K, Benjouad A, Rochat H, Duval A et al. Evidence for neurotoxic activity of tat from human immunodeficiency virus type 1. J Virol 1991; 65: 961-967.

36 Barks JD, Nair MP, Schwartz SA, Silverstein FS. Potentiation of N-methyl-Daspartate-mediated brain injury by a human immunodeficiency virus-1-derived peptide in perinatal rodents. Pediatr Res 1993; 34: 192-198.

37 Bao L, Guo H, Huang X, Tammana S, Wong M, Mclvor RS et al. High-titer lentiviral vectors stimulate fetal calf serum-specific human CD4 T-cell responses: implications in human gene therapy. Gene Ther 2009; 16: 788-795.
38 Hutson TH, Foster E, Dawes JM, Hindges R, Yáñez-Muñoz RJ, Moon LD. Lentiviral vectors encoding short hairpin RNAs efficiently transduce and knockdown LINGO1 but induce an interferon response and cytotoxicity in central nervous system neurones. J Gene Med 2012; 14: 299-315.

39 Zufferey R, Dull T, Mandel RJ, Bukovsky A, Quiroz D, Naldini L et al. Self-inactivating lentivirus vector for safe and efficient in vivo gene delivery. J Virol 1998; 72: 9873-9880.

40 Dull T, Zufferey R, Kelly M, Mandel RJ, Nguyen M, Trono D et al. A thirdgeneration lentivirus vector with a conditional packaging system. J Virol 1998; 72: 8463-8471.

41 Sena-Esteves M, Tebbets JC, Steffens S, Crombleholme T, Flake AW. Optimized large-scale production of high titer lentivirus vector pseudotypes. $J$ Virol Methods 2004; 122: 131-139.

42 Estevez AG, Sampson JB, Zhuang YX, Spear N, Richardson GJ, Crow JP et al. Liposome-delivered superoxide dismutase prevents nitric oxide-dependent motor neuron death induced by trophic factor withdrawal. Free Radic Biol Med 2000; 28: 437-446.

43 Saneto RP, De Vellis J. Neuronal and glial cells: cell culture of the central nervous system. In: Turner AJ, Brachelard HS (eds). Neurochemistry: A Practical Approach. IRL Press: Washington DC, 1987, pp 27-63.

44 Cassina P, Peluffo H, Pehar M, Martinez-Palma L, Ressia A, Beckman JS et al. Peroxynitrite triggers a phenotypic transformation in spinal cord astrocytes that induces motor neuron apoptosis. J Neurosci Res 2002; 67: 21-29.

45 Saura J, Tusell JM, Serratosa J. High-yield isolation of murine microglia by mild trypsinization. Glia 2003; 44: 183-189. 